\title{
Microstructure and Durability Properties of Lightweight and High-Performance Sustainable Cement-Based Composites with Rice Husk Ash
}

Gökhan Kaplan ( $\sim$ gkaplan@atauni.edu.tr)

Ataturk University: Ataturk Universitesi https://orcid.org/0000-0001-6067-7337

Mohamed A.Salem Elmekahal

Kastamonu University: Kastamonu Universitesi

\section{Research Article}

Keywords: Rice husk ash, Sustainability, Durability, Acid resistance, Ettringite

Posted Date: April 5th, 2021

DOl: https://doi.org/10.21203/rs.3.rs-337672/v1

License: (c) (1) This work is licensed under a Creative Commons Attribution 4.0 International License.

Read Full License 


\section{Abstract}

Sustainable solutions are investigated to reduce the environmental damage caused by greenhouse gases and $\mathrm{CO}_{2}$ emissions. Cement is a construction material responsible for greenhouse gases and $\mathrm{CO}_{2}$ emissions. Thus, $\mathrm{CO}_{2}$ emissions are reduced by using replacement materials such as rice husk ash instead of cement. This study investigated the durability and mechanical properties of lightweight and high-performance, sustainable cement-based composites. A foaming agent was used to reducing the unit weight of the mixtures. Also, pumice powder (PP) and rice husk ash (RHA) were used to improve cementbased composites' durability and mechanical properties. The density of mixtures varies between 1666$2205 \mathrm{~kg} / \mathrm{m}^{3}$. The early age strength of the mixes using $12.5 \%$ RHA has increased. The mixtures' compressive strength (91-days) with 25\% RHA and 50\% PP was $46.6 \mathrm{MPa}$. As the PP content of mixes increased, drying shrinkage values increased. Expansions decrease as the initial compressive strength increases in mixtures exposed to sulfate. As RHA and PP's ratio increased, weight loss decreased in mixes exposed to $\mathrm{HCl}$, while weight loss increased in mixes exposed to $\mathrm{H}_{2} \mathrm{SO}_{4}$. It was determined that the content of $\mathrm{CH}(\mathrm{OH})_{2}$ is important in mixes exposed to $\mathrm{HCl}$, and impermeability is important in mixes exposed to $\mathrm{H}_{2} \mathrm{SO}_{4}$. It has been observed that the initial compressive strength is also important in mixes exposed to the freeze-thaw effect. As the foam content of the mixes increased, the compressive strength decreased while the drying shrinkage increased. As a result, using up to $25 \%$ RHA has increased the performance of cement-based composites.

\section{Introduction}

High-performance mortar and concrete are widely used worldwide due to their superior properties compared to conventional concrete. High strength and elasticity modulus, enough workability, better impact, and abrasion resistance are some of the high-performance mortars' properties (Danish ve Mosaberpanah 2021). The American Concrete Institute (ACl) has defined some properties related to highperformance cement-based composites (B. Muhit, S. S. Ahmed et al. 2013). Properties such as costeffectiveness, sustainability, and enormous application areas have increased the popularity of highperformance mortars. (De Gutiérrez et al. 2005). Population growth and industrial development in the world have increased the usability of cement-based composites. As a result of the increase in the use of cement-based composites, the demand for cement has also increased. With the rise in cement consumption globally, $\mathrm{CO}_{2}$ emissions and environmental pollution have also increased (Shaikuthali et al. 2019). Thus, the cement and concrete industry is looking for alternative solutions for sustainable construction material design. The use of wastes generated as a result of industrial activities has been the most common method. The use of industrial wastes as cement replacement material reduces environmental pollution and increases composites' performance (Rafieizonooz et al. 2016). Fly ash, blast furnace slag, silica fume, bottom ash and rice husk ash are the most usually used cement replacement materials. 
The use of ashes obtained from waste biomass as cement replacement material helps the recycling of organic wastes. The storage and incineration of these wastes are very harmful to the environment (Gupta et al. 2018; Thomas 2018). The most common of this type of waste is rice husk, an agricultural byproduct formed during paddy rice's dehusking process. The population increase in the world increases the rice consumption day by day. It is estimated that 500 billion tons of rice is produced worldwide, and approximately $20 \%$ of this mass is rice husk (Bhanumathidas ve P. kumar 2001). It is estimated that 769.9 million tons of rice were obtained from paddy fields in 2018 (FAO 2018). Rice crust is more exposed in countries such as China, India, Bangladesh, Thailand, Indonesia, Vietnam, and the Philippines, where rice is the staple food (Pode 2016). The International Rice Research Institute (IRRI) and Food and Agriculture Organization (FAO) stated that in 2018, India produced approximately 32 million tons of rice husk (FAO 2018). Rice husk can decompose in natural conditions because its siliceous content is resistant to natural decomposition (Madandoust et al. 2011). As a result of burning the rice husks, 20$30 \%$ ash is obtained. Rice husk ash (RHA) contains highly amorphous silica. It is widely used to improve the fresh and hardened properties of concrete (Le ve Ludwig 2016; Park et al. 2016). The rice husk's burning temperature and process are the parameters that most affect the cement and concrete properties. In rural areas, rice husk is generally burned at $300-400{ }^{\circ} \mathrm{C}$. In developing countries, rice husk can be disposed of in this way (Singh et al. 2016). Due to low density, RHA particles can fly in the air, increasing environmental pollution. Also, uncontrolled combustion below $500^{\circ} \mathrm{C}$ causes incomplete combustion, as a result of which the pozzolanic activity of the ash decreases due to the presence of unburned carbon (AlKhalaf ve Yousif 1984). The RHA's pozzolanic reactivity depends on the reactive silica content, ash particle size, combustion conditions, and carbon content. The mobilization of silica from RHA is the first parameter that determines the material's reactivity (Givi et al. 2010). It has been reported in the literature that RHA increases CSH formation, improves acid and sulfate resistance, and decreases chloride penetration (Ganesan et al. 2008; Gursel et al. 2016; Olutoge ve Adesina 2019). Due to RHA's use, environmental pollution will be reduced, and $\mathrm{CO}_{2}$ emissions caused by cement will also be reduced (Thomas 2018). Many sustainable cement and concrete production applications have been proposed in the literature (Bekem Kara ve Durmuş 2019; Bayraktar 2021; Kaplan et al. 2021; Toklu 2021).

Nowadays, much research is done for alternative binders that can be used instead of cement that causes environmental problems. The construction sector carries out these researches with parameters such as economy, sustainability, and technology. Thus, it is crucial to use cement replacement materials in cement and concrete production (Hossain 2003). The cement industry is responsible for $7 \%$ of the world's $\mathrm{CO}_{2}$ emissions. Therefore, researches are carried out for sustainable solutions (Mehta 1999). Industrial wastes are used in cement-based composites as well as volcanic minerals. Volcanic minerals or natural pozzolans also have pozzolanic properties. Some natural pozzolan reserves, such as pumice, are rich and successfully used in industrial projects (Tikalsky et al. 2001). Although pumice is a rock of volcanic origin, it has pozzolanic properties. It produces new CSH gels by reacting with the lime in the paste. The strength and durability of cement-based composites using pumice powder (PP) are improving (Hossain 2003). As the particle size of PP decreases or the specific surface area increases, the compressive strength increases more (Seraj et al. 2017). The chemical and mineralogical composition of natural 
pozzolans has a direct effect on pozzolanic activity (Tikalsky et al. 2001). The acidic or basic form of pumice is another factor affecting the pozzolanic activity. Lightweight construction materials are generally produced using pumice. Also, pumice improves the thermal properties of cement-based composites. Thus, cement-based composites produced with pumice will help reduce $\mathrm{CO}_{2}$ emission.

Foam concrete is a type of lightweight concrete obtained by mixing foam and mortar. Foam concrete was first produced in 1911 by the Danish engineer Bayer (Namsone et al. 2017). Due to its porous structure, foam concrete's unit weight has many advantages compared to conventional concrete. The foam concretes' density varies between $300-1800 \mathrm{~kg} / \mathrm{m}^{3}$ depending on the area of use (Amran et al. 2015). Foam concrete with a density of $300-600 \mathrm{~kg} / \mathrm{m}^{3}$ is used for insulation. Foam concrete with a density of $600-1200 \mathrm{~kg} / \mathrm{m}^{3}$ is used to produce non-structural elements, while foam concrete with a $1200-1800$ $\mathrm{kg} / \mathrm{m}^{3}$ is used to produce structural elements (Raj et al. 2019). Foam concrete is generally used for thermal and acoustic insulation (Chung et al. 2019; Alnahhal et al. 2021). The essential material in the production of foam concrete is the foaming agent. Surfactants, hydrogen peroxide, aluminum powder, SLS, and carbon powder are used as foaming agents (Masi et al. 2014; Narasimman et al. 2014; Sun et al. 2018). Foam concrete has high water absorption capacity and low mechanical properties (Sun et al. 2018). The porous structure is the most important factor that reduces its mechanical properties (Falliano et al. 2018a). The mechanical properties of foam concrete depend on the water to cement ratio, air to cement ratio, foam agent type, and foam volüme (Falliano et al. 2018b). As the sand to cement ratio of foam concrete increases, compressive strength decreases (Hamidah et al. 2005). The high porosity of foam concrete reduces the thermal conductivity coefficient. Therefore, energy conservation is provided by the composites produced with foam concrete (Abdollahnejad et al. 2015). If energy conservation is provided in buildings, less energy will be used for heating and cooling. $\mathrm{CO}_{2}$ emissions will be reduced by saving energy. Thus, the use of foam concrete is an essential solution for sustainable building design.

\section{Experimental Study}

This study investigated the mechanical and durability properties of lightweight and high-performance cement-based composites. Three different methods are used to reduce the unit weights of cement-based composites. In the first method, pumice powder (natural pozzolana) with a specific gravity lower than cement was used as a binder. In the second method, a foaming agent is used in the production of cement-based composites. In the third method, scoria aggregate with a lower specific gravity was used. This context aims to produce composites with a unit weight below $2000 \mathrm{~kg} / \mathrm{m}^{3}$ but high durability.

\section{Raw Materials}

Figure 1 shows the materials used in the production of cement-based composites. Cement-based composites were obtained using scoria aggregate, cement, pumice powder, rice husk ash, foam, Superplasticizer, and water.

\section{Scoria Aggregate}


Scoria is used as light aggregate instead of normal aggregate in the mixes. Scoria is sourced from the Uşak region in southwestern Turkey. Scoria was provided from the Uşak region in southwestern Turkey. The sieve size of Scoria, which is a fine aggregate, is between $0-4 \mathrm{~mm}$. The physical characteristics of Scoria are shown in Table 1.

Table 1. Properties of the Scoria aggregate

\begin{tabular}{|c|c|}
\hline \multicolumn{2}{|c|}{ Physical properties } \\
\hline Specific gravity & 2.42 \\
\hline Water absorption (\%) & 0.85 \\
\hline Finen & 3.12 \\
\hline Silt & 0.58 \\
\hline $\mathrm{SiO}_{2}+$ & 56.7 \\
\hline
\end{tabular}

\section{Cement and Cement Replacement Materials}

Cement was used as the main binder in the mixtures. Pumice powder (PP) and rice husk ash (RHA) were used as a cement replacement material. CEM I 42.5 R cement by EN 197-1 standard was preferred for mixes. The chemical and physical properties of cement RHA and PP are given in Table 2. RHA and PP are obtained by grinding 30 and 60 minutes in a ball mill. RHA is produced by natural combustion using a stove.

Table 2. Chemical and physical properties of Cement RHA and PP

\begin{tabular}{|c|c|c|c|c|}
\hline \multirow{10}{*}{$\begin{array}{l}\text { Chemical } \\
\text { Properties }\end{array}$} & (\%) & CEM I 42.5R & PP & RHA \\
\hline & $\mathrm{CaO}$ & 63.2 & 2.1 & 93.6 \\
\hline & $\mathrm{SiO}_{2}$ & 20.2 & 67.3 & 0.8 \\
\hline & $\mathrm{Al}_{2} \mathrm{O}_{3}$ & 5.2 & 11.1 & 0.2 \\
\hline & $\mathrm{Fe}_{2} \mathrm{O}_{3}$ & 3.3 & 1.8 & 0.3 \\
\hline & $\mathrm{MgO}$ & 1.7 & 0.6 & 0.4 \\
\hline & $\mathrm{Na}_{2} \mathrm{O}$ & 0.3 & 2.1 & 0.7 \\
\hline & $\mathrm{K}_{2} \mathrm{O}$ & 0.7 & 3.9 & 1.1 \\
\hline & $\mathrm{SO}_{3}$ & 3.2 & 0.1 & 0.1 \\
\hline & LOI & 2.2 & 6.8 & 2.5 \\
\hline \multirow[t]{5}{*}{ Physical Properties } & Specific gravity & 3.13 & 1.34 & 2.17 \\
\hline & Blaine fineness $\left(\mathrm{cm}^{2} / \mathrm{g}\right)$ & 3300 & 3900 & 13200 \\
\hline & Volumetric expansion (mm) & 1.7 & - & \\
\hline & Initial set (min) & 160 & - & \\
\hline & Final set (min.) & 200 & - & \\
\hline
\end{tabular}

Figure 2 shows the XRD graph of the RHA. It has been determined that RHA consists of quartz and cristobalite minerals. It also seems that the content of the vitreous phase is high

\section{Foam Agent}

A foaming agent was used to reducing the unit weight of cement-based composites. The foaming agent is based on organic resin. The properties of the foaming agent are given in Table 3 . It is aimed to obtain 
independent closed cells in composite with produced foam.

Table 3. Properties of foaming agent

\begin{tabular}{ccc}
\hline Chemical Contents & \multicolumn{2}{c}{ Organic resin } \\
\hline Appearance-Colour & \multicolumn{2}{c}{ Translucent, pale brown liquid } \\
\hline Density & $1.03 \pm 0.02 \mathrm{~kg} / \mathrm{l}$. & ISO 758 \\
\hline pH Value & $5.0 \pm 1$ & TS 6365 EN 1262 \\
\hline Chloride Content (Cl) & $<\% 0.1$ & TS EN 480-10 \\
\hline Alkali Content & $<\% 5$ & TS EN 480-12 \\
\hline Freezing Point & $-5 \circ \mathrm{C}$ & \\
& & \\
\hline
\end{tabular}

\section{Superplasticizer}

The water/binder $(\mathrm{w} / \mathrm{b})$ ratio has been reduced to increase cement-based composites' strength and durability. Polycarboxylate based superplasticizer (SP) was used to prevent loss of workability due to decreased $\mathrm{w} / \mathrm{b}$ ratio. The specific gravity of the superplasticizer is 1.05 , and the solids content is $35 \%$. Superplasticizer was added to the mixture according to the total amount of binder.

\section{Sample Preparations and Curing}

All tests of cement-based composites were carried out on three samples. Hobart type mixer was used in the preparation of the mixtures. The $\mathrm{w} / \mathrm{b}$ ratio of the mixes was 0.35 , and the binder dosage was $450 \mathrm{~kg}$. The density of foam prepared with the foaming agent is $120 \mathrm{~g} / \mathrm{l}$. PP was used to reduce the unit volume weight of the paste. Pumice powder was used in $25 \%$ and $50 \%$ of cement weight. RHA has been used to prevent reductions that PP can cause in mechanical properties. RHA used $12.5 \%$ and $25 \%$, according to cement weight. Unit weights of cement-based composites were reduced by the addition of 12.5 and 25 $\mathrm{kg} / \mathrm{m}^{3}$ of foam. Mixing ratios and material amounts are given in Table 4.

Table 4. Mixing parameters 


\begin{tabular}{|c|c|c|c|c|c|c|c|c|c|c|}
\hline \multirow{2}{*}{$\begin{array}{l}\text { Mix } \\
\text { ID }\end{array}$} & \multicolumn{3}{|c|}{ Mix ratios } & \multicolumn{7}{|c|}{ Material amounts $\left(\mathrm{kg} / \mathrm{m}^{3}\right)$} \\
\hline & $\begin{array}{c}\text { Foam } \\
\text { content } \\
(\mathrm{kg} / \mathrm{m} 3)\end{array}$ & $\begin{array}{c}\text { RHA } \\
(\%)\end{array}$ & $\begin{array}{l}\text { PP } \\
\text { (\%) }\end{array}$ & Cement & $\mathrm{PP}$ & RHA & Scoria & Water & SP & Foam \\
\hline 1 & 12.5 & 0 & 0 & 450,0 & 0,0 & 0,0 & 382,8 & 157,5 & 2,7 & 12,5 \\
\hline 2 & & & 25 & 337,5 & 112,5 & 0,0 & 287,0 & 157,5 & 13,5 & 12,5 \\
\hline 3 & & & 50 & 225,0 & 225,0 & 0,0 & 217,1 & 157,5 & 13,5 & 12,5 \\
\hline 4 & & 12.5 & 0 & 393,8 & 0,0 & 56,3 & 338,5 & 157,5 & 13,5 & 12,5 \\
\hline 5 & & & 25 & 281,3 & 112,5 & 56,3 & 268,5 & 157,5 & 13,5 & 12,5 \\
\hline 6 & & & 50 & 168,8 & 225,0 & 56,3 & 198,5 & 157,5 & 13,5 & 12,5 \\
\hline 7 & & 25 & 0 & 337,5 & 0,0 & 112,5 & 319,9 & 157,5 & 13,5 & 12,5 \\
\hline 8 & & & 25 & 225,0 & 112,5 & 112,5 & 249,9 & 157,5 & 13,5 & 12,5 \\
\hline 9 & & & 50 & 112,5 & 225,0 & 112,5 & 179,9 & 157,5 & 13,5 & 12,5 \\
\hline 10 & 25 & 0 & 0 & 450,0 & 0,0 & 0,0 & 278,6 & 157,5 & 2,7 & 25,0 \\
\hline 11 & & & 25 & 337,5 & 112,5 & 0,0 & 182,9 & 157,5 & 13,5 & 25,0 \\
\hline 12 & & & 50 & 225,0 & 225,0 & 0,0 & 112,9 & 157,5 & 13,5 & 25,0 \\
\hline 13 & & 12.5 & 0 & 393,8 & 0,0 & 56,3 & 234,3 & 157,5 & 13,5 & 25,0 \\
\hline 14 & & & 25 & 281,3 & 112,5 & 56,3 & 164,3 & 157,5 & 13,5 & 25,0 \\
\hline 15 & & & 50 & 168,8 & 225,0 & 56,3 & 94,3 & 157,5 & 13,5 & 25,0 \\
\hline 16 & & 25 & 0 & 337,5 & 0,0 & 112,5 & 215,8 & 157,5 & 13,5 & 25,0 \\
\hline 17 & & & 25 & 225,0 & 112,5 & 112,5 & 145,8 & 157,5 & 13,5 & 25,0 \\
\hline 18 & & & 50 & 112,5 & 225,0 & 112,5 & 75,8 & 157,5 & 13,5 & 25,0 \\
\hline
\end{tabular}

Cement-based composites were stored in laboratory conditions for 24 hours after casting. The composites demolding from their molds were kept in water curing until the experiment day. Potable water was used in the mixtures and curing process.

\section{Test Methods}

\section{Workability}

The Workability of cement-based composites has been determined using the flow table. The flow diameters of mortars were determined by ASTM C 1437 (ASTM 2013) standard. The cement-based composites' flow diameters were determined by the average length of the $\mathrm{X}$ and $\mathrm{Y}$ directions.

\section{Physical Properties}

Physical properties of cement-based composites such as apparent porosity, water absorption, and dry bulk density were determined. Physical properties of cement-based composites were determined after 90 days of curing period. Physical properties were determined on 50x50x50 mm cube specimens. Physical properties were measured by the ASTM C642 (ASTM C642-13 2013) standard. Oven-dried samples were obtained by drying at $50^{\circ} \mathrm{C}$ for three days.

\section{Mechanical Properties}


Flexural and compressive strengths of cement-based composites were determined on the $1^{\text {st }}, 7^{\text {th }}, 28^{\text {th }}$, and $90^{\text {th }}$ days. The flexural strength of cement-based composites was carried out according to ASTM C348 (ASTM C348 1998) standard. Prism samples in 40×40×160 mm are produced for flexural strength. Compressive strength was determined according to ASTM C349 (ASTM C349 2002) in the samples obtained after the three-point flexural experiment.

\section{Drying Shrinkage}

The drying shrinkage of cement-based composites was measured for 120 days. Time-dependent change of drying shrinkages was measured on $25 \times 25 \times 285 \mathrm{~mm}$ mortar bars. Cement-based composites were stored in laboratory conditions after seven days of water curing. The drying shrinkage test was performed by the ASTM C596 (ASTM C 596-01 2001) standard. The length of the mortar bars was measured once in seven days. Length changes of cement-based composites were determined with a digital comparator.

\section{Capillarity}

The time-dependent water penetration depths of the composites were determined according to the ASTM

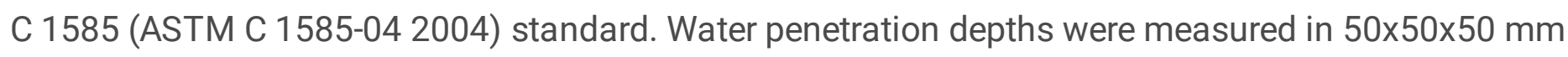
cube samples. The capillarity test was carried out on oven-dried samples. Oven-dried samples were obtained by drying at $50^{\circ} \mathrm{C}$ for three days. A waterproofing agent was applied to the side surfaces of the samples (approximately $1 \mathrm{~cm}$ ). In this way, it is ensured that the water only moves in the vertical direction. Water penetration depths were determined on samples cured for 90 days. The water penetration depth was measured up to the $28^{\text {th }}$ day.

\section{Sulfate Resistance}

The sulfate resistance of cement-based composites is determined according to ASTM C1012 (ASTM C1012 2004) standard. $\mathrm{Na}_{2} \mathrm{SO}_{4}(\% 5)$ solution was used for sulfate resistance. Cement-based composites were exposed to $\mathrm{Na}_{2} \mathrm{SO}_{4}$ after 90 days of curing. The sodium sulfate solution was renewed every month. Mortar bars of $25 \times 25 \times 285 \mathrm{~mm}$ were used to determine the sulfate resistance. The length of the mortar bars was measured for 150 days. The expansions caused by sodium sulfate were measured with a digital comparator.

\section{Acid Resistance}

The acid resistance of cement-based composites was determined using $\mathrm{HCl}$ and $\mathrm{H}_{2} \mathrm{SO}_{4}$ solutions. $\mathrm{HCl}$ and $\mathrm{H}_{2} \mathrm{SO}_{4}$ solutions were prepared at a ratio of $5 \%$. The acid resistance of cement-based composites was investigated according to ASTM C 1152 (ASTM International) standard. Mass changes of samples in acid solutions were measured for 150 days. Acid solutions are renewed every month. Mass losses were measured on $40 \times 40 \times 160 \mathrm{~mm}$ prism specimens. Cement-based composites were exposed to the acid solution after 90 days of curing. Mass losses of cement-based composites were determined using Eq. 1 . 
$\left(m_{i}-m_{t}\right) / m_{i}^{*} 100$

where

$\mathrm{m}_{\mathrm{i}}$ : Initial mass of the sample

$\mathrm{m}_{\mathrm{t}}:$ The mass of the sample after $\mathrm{t}$ days

\section{Freezing and Thawing}

ASTM C666 (Astm C666/C666M 2003) standard has been used for the freeze-thaw resistance of cement-

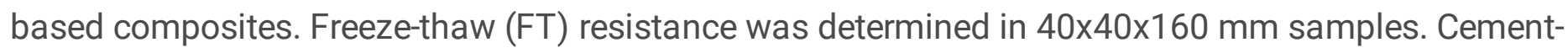
based composites were exposed to 100 and 200 freeze-thaw cycles. The relative dynamic elasticity modulus (RDEM) and the samples' mechanical properties were measured in each cycle. Also, ultrasonic pulse velocity (UPV) (American Society of Testing and Materials 2016) was measured to determine the samples' degree of damage. Cement-based composites were exposed to the freeze-thaw effect after 90 days of curing. In the cycles, the freezing time was set to 7 hours and the thaw time to 5 hours (Two cycles per day).

\section{Microstructure Investigations}

Microstructures of cement-based composites exposed to sulfate and acid effects were examined with scanning electron microscopy (SEM). SEM images were obtained in different magnifications. Also, elemental analysis (EDS) was carried out to examine hydration products. SEM and EDS analyzes were carried out in the DAYTAM unit of Atatürk University. The equipment used in the experimental study is given in Figure 3.

\section{Results And Discussions}

\section{Fresh properties of cement-based composites}

Figure 4 shows that the flow diameters increase as the foam content increases. As a result of increasing the ratio of RHA, the flow diameters of composites decrease. However, in mixtures where the RHA ratio is $0 \%$, an increase in the PP ratio improves workability. The higher the PP ratio, the better the workability as the paste volume will increase. In composites with a foam content of $12.5 \mathrm{~kg} / \mathrm{m}^{3}$, the flow diameter was measured at $12.4 \mathrm{~cm}$ if the RHA ratio was $25 \%$ and the PP ratio was $50 \%$. The high rate of PP and RHA use, porous and finer than cement, reduced the flow diameter by approximately $50 \%$ compared to the reference (RHA0-PP0). A similar effect was not observed if the foam content was $25 \mathrm{~kg} / \mathrm{m}^{3}$. Because the increase in the foam content generally increases the workability. If the foam content is $12.5 \mathrm{~kg} / \mathrm{m}^{3}$, the flow diameter ranges from 12.4-47.8 cm, and the foam content of $25 \mathrm{~kg} / \mathrm{m}^{3}$ ranges from $27.9-52.5 \mathrm{~cm}$. It was determined that RHA12 and RHA 25 samples showed similarities in the foam content of $25 \mathrm{~kg} / \mathrm{m}^{3}$. In these mixtures, the PP ratio of $50 \%$ reduces the flow diameter by $13-15 \%$. If the PP ratio is $50 \%$, the loss of 
consistency occurs more. Especially in low foam content, the increase in PP ratio negatively affects the workability.

Karataş et al. have been observed that the workability decreases in the use of 5 and $10 \%$ PP, but the workability increases when $25 \%$ PP is used (Karataş et al. 2017). It has been noted that the non-spherical particle shape and porous structure of PP reduce workability (Granata 2015). In the study conducted by Zeyad and Almalki, the flow diameters increased due to the increase in PP ratio (Zeyad ve Almalki 2021). The literature stated that workability increases if mineral admixtures are used instead of cement because the voids in the interface decrease, the friction between the aggregate particles decreases. The utilization of the mineral admixtures as partial replacement to cement with constant $\mathrm{w} / \mathrm{c}$ ratio obtains high cement paste wetting, thereby improving workability. Also, reducing the amount of cement in the mixture decreases agglomeration due to electrical charge (Jiang ve Malhotra 2000; Mehta 2004). Abbas et al., up to $40 \%$ used RHA instead of cement. As a result of the experimental study, consistency losses were not observed, despite RHA's high use (Abbas et al. 2017). However, it has been stated that RHA will increase the water demand due to its high specific area and hygroscopic properties (Hossain et al. 2011). Chandni and Anand used more foam to reduce the density of the mixes. As a result of the mixture's foam content increase, the flow diameters decreased (Chandni ve Anand 2018). Because the increase in foam content raises the number of bubbles and reduces the workability (Nambiar ve Ramamurthy 2006). She et al. determined that the flow diameter increases as the foam content increases in the concretes made using completely sand (She et al. 2018). Gowri and Anand stated that as the foam content increased, the mixture's water demand increased (Gowri ve Anand 2018). In the study conducted by Eltayeb et al., the flow diameters improve as the foam content increases (Eltayeb et al. 2020).

In this study, flow diameters improved as the foam content increased. The foaming agent caused the paste to expand by acting as an air-entraining admixture. As a result of the expansion of the paste, workability has increased. Also, the small amount of water content in the foam has increased the workability. Since PP reduces the friction between aggregate grains, it has been determined that the optimum ratio is $25 \%$. The use of $50 \%$ PP can significantly reduce workability in low foam content. It is also recommended to use $12.5 \%$ RHA in low foam content. Foam content should also be increased if high RHA levels (\%25) reduce environmental pollution.

\section{Physical Properties Of Cement-Based Composites}

Figure 5 shows the physical properties of cement-based composites. The left axis shows the column graphs, and the right axis shows the values of the circle icons. Porosity and water absorption values decreased if the RHA content was $12.5 \%$ in mixtures with a foam content of $12.5 \mathrm{~kg} / \mathrm{m}^{3}$. The porosity values of mixtures with a foam content of $12.5 \mathrm{~kg} / \mathrm{m}^{3}$ range from $4.8 \%$ to $14.8 \%$. The water absorption values of mixtures with a foam content of $12.5 \mathrm{~kg} / \mathrm{m}^{3}$ range from 2.4 to $8.9 \%$. In mixtures with a foam content of $12.5 \mathrm{~kg} / \mathrm{m}^{3}$, porosity and water absorption values increased if the RHA ratio was $25 \%$ and the PP ratio was $50 \%$. Because the workability of these mixtures is very low, porosity and water absorption 
values have increased. If the RHA content is $25 \%$ in low foam content, the PP must be a maximum of $25 \%$.

If the foam content is $50 \mathrm{~kg} / \mathrm{m}^{3}$, the apparent porosity value ranges from 7.3 to $21.6 \%$. If the foam content is $50 \mathrm{~kg} / \mathrm{m}^{3}$, the water absorption ratio varies between 3.7-13.6\%. Porosity and water absorption rates increase when the RHA rate is $12.5 \%$ in mixtures with a foam content of $50 \mathrm{~kg} / \mathrm{m}^{3}$. But if RHA is $25 \%$, porosity and water absorption rates are relatively reduced. A low foam content of RHA of $12.5 \%$ reduces porosity and water absorption rates, while the opposite has been observed in high foam content. In mixtures with low workability, using materials with an optimal rate and a high specific surface area can reduce porosity and water absorption. In mixes with high workability, a large number of air bubbles prevent these materials from reducing porosity. In high foam contents, using cement replacement materials at high rates can reduce porosity. As the PP ratio increases, porosity and water absorption rates increase because PP's porosity affects physical properties. As the workability of the mixtures decreases, the porosity and water absorption rates generally increase.

Figure 6 shows that as the foam content and PP ratio increase, the bulk densities of cement-based composites decrease. Bulk densities of cement-based composites vary between $1666-2205 \mathrm{~kg} / \mathrm{m}^{3}$. Increasing the RHA ratio did not affect bulk density values much. However, if PP is used $25 \%$ and above, the bulk densities have descended below $2000 \mathrm{~kg} / \mathrm{m}^{3}$. Bulk densities of mixtures used in $50 \%$ PP are usually below $1800 \mathrm{~kg} / \mathrm{m}^{3}$. Dry bulk density values decrease by $16-19 \%$ if $\mathrm{PP}$ is $50 \%$ and foam content is $25 \mathrm{~kg} / \mathrm{m}^{3}$. When using RHA at $25 \%$ instead of $12.5 \%$, the bulk density values increased slightly. As RHA fills the voids between cement particles, bulk density values have increased.

A high $R^{2}$ value (0.98) has been observed between apparent porosity and water absorption (Fig. 7). As the porosity values of the mixtures increase, the water absorption rates tend to increase. $A$ value of $R^{2}$ between the apparent porosity and bulk density was obtained as 0.86 . As the porosity of cement-based composites increases, the bulk density of the mixtures decreases. The porosity values of mixtures with bulk density below $1800 \mathrm{~kg} / \mathrm{m}^{3}$ are $14.5 \%$ and above.

Chindaprasirt and Rukzon showed that the porosity increased as the RHA content increased (Chindaprasirt ve Rukzon 2008). The use of fine-grained materials such as RHA in mixtures leads to the segmentation of large pores (Mehta 1989). Xu et al. it has been noted that if used in mixes of RHA with adequate fineness, it reduces porosity (Xu et al. 2015). In the study conducted by Rodrigues and Ghavami, as the RHA content increased, porosity values increased while bulk density values decreased (De Souza Rodrigues et al. 2006). Karataş et al. was determined that as the PP ratio increased, the porosity increased, and the bulk density decreased (Karataş et al. 2017). The rough and porous structure of PP is effective on porosity and bulk density (Kabay et al. 2015). Zeyad et al. was determined that as the PP content increased, the water absorption ratio of the mixtures decreased (Zeyad et al. 2019). This effect has also been observed in mortars and concretes produced with volcanic ash (Siddique 2012). In Pasupathy's study, as the foam content was raised, the porosity values increased (Pasupathy et al. 2020). 
Köksal et al. stated that as the foam content increased, the porosity and water absorption rate increased, but the density decreased (Koksal et al. 2020). As the foam content increases, the number of air bubbles in the mixture rises. Thus, while the porosity of mixtures increases, their bulk density tends to decrease. Also, mineral additives indirectly change the physical properties as they affect the workability.

\section{Mechanical Properties of Cement-Based Composites}

Figure 8a shows that cement-based composites' compressive strength for one day varies between 4.844.7 MPa. In mixtures with low foam content $\left(12.5 \mathrm{~kg} / \mathrm{m}^{3}\right)$, the RHA content of $12.5 \%$ can increase compressive strength. But if the PP ratio is $50 \%$ in these mixtures, the compressive strength has decreased below $15 \mathrm{MPa}$. The compressive strength of mixes with an RHA ratio of $25 \%$ and a PP ratio of $50 \%$ was reduced by $89.3 \%$ compared to mixes without RFA and PP (Reference mix). Approximately 45 $\mathrm{MPa}$ compressive strength was achieved if $12.5 \%$ RHA was used in mixes without PP. If the PP ratio is $50 \%$, the 1-day compressive strength is usually below $15 \mathrm{MPa}$.

Compressive strengths of $30 \mathrm{MPa}$ and above were obtained in 1 day in mixtures without PP with high foam content $\left(25 \mathrm{~kg} / \mathrm{m}^{3}\right)$. The compressive strength of mixtures with a PP ratio of $50 \%$ is usually below $10 \mathrm{MPa}$. Compressive strength of mixtures without PP and RHA rate of $12.5 \%$ increased $4.8 \%$ compared to mixtures without PP and RHA.

1-day flexural strength of mixtures with low foam content ranges from 1.5-5.7 MPa. As the RHA ratio increases in mixes without PP, the flexural strength of the mixtures increases. If the PP ratio is $25 \%$ and $50 \%$, the flexural strength decreases as the RHA ratio increases. In particular, the flexural strength of mixtures with a PP ratio of $50 \%$ is less than $3.5 \mathrm{MPa}$. The flexural strength of mixes without PP with an RHA ratio of $25 \%$ increased by $23.9 \%$ compared to mixes without PP and RHA. Increasing the foam content in the mixtures decreases the flexural strength. Especially in mixtures with a high rate of cement replacement materials (PP- 50\%, RHA- 25\%), the flexural strength has decreased to $0.8 \mathrm{MPa}$. The increase in the RHA ratio was more effective on the flexural strength. Such an effect has been observed as the high $\mathrm{SiO}_{2}$ content, and specific surface area of RHA improve the aggregate-paste interface. Mechanical properties are negatively affected due to PP's low pozzolanic properties.

As shown in Figure 8b, as the foam content increases, the 7-day compressive strength decreases. 7-day compressive strength of mixtures with $25 \mathrm{~kg} / \mathrm{m}^{3}$ foam content varies between 35.7-69.3 MPa. As the RHA content rises in mixes without PP, the compressive strength increases. If the PP is $25 \%$ in mixtures without RHA, the compressive strength has increased by $15.1 \%$ compared to the reference mixture. In mixtures where PP is used at $50 \%$, the compressive strength decreases as the RHA content increases. Similar results were observed with mixtures with high foam content $\left(25 \mathrm{~kg} / \mathrm{m}^{3}\right)$. Compressive strengths of $50 \mathrm{MPa}$ and above were obtained in all cement-based composites except for $50 \%$ PP mixtures.

The 7-day flexural strength of cement-based composites changes between 2.8-6.3 MPa. Flexural strength increases as RHA content increases in low foam content, while flexural strength decreases in high foam 
content. If the PP ratio is $25 \%$ at low foam content, flexural strength generally increases. It has been determined that if the RHA ratio is $25 \%$ in high foam content, it does not affect PP's flexural strength.

The 28-day compressive strength of cement-based composites varies between 37.9-78.9 MPa (Fig 8c). Increased curing time greatly improved compressive strength. Increasing the foam content slightly reduces compressive strength. When the RHA content was $12.5 \%$, and PP was $0 \%$ in mixtures with low foam content, the compressive strength increased by $14.3 \%$ compared to the reference mixture. Although the foam content was $25 \mathrm{~kg} / \mathrm{m}^{3}$, if the RHA was $12.5 \%$ and PP was $0 \%$, compressive strength of approximately $78 \mathrm{MPa}$ was obtained. The use of PP at a rate of $25 \%$ in mixtures without RHA increases their compressive strength.

The 28-day flexural strength of cement-based composites without PP is between 5.4-6.8 MPa. As PP ratio and foam content increase, flexural strength generally decreases. In mixtures without PP, an RHA content of $12.5 \%$ increases the flexural strength.

Figure 8d shows that the 90-day compressive strength of mixtures decreases as the foam content increases. The compressive strength of mixes ranges from 42.1-84.3 MPa. The change in RHA ratio in low foam content does not affect the compressive strength much. If RHA is used in mixtures without PP, compressive strengths of $80 \mathrm{MPa}$ and above are obtained. In high foam content, this value is $70 \mathrm{MPa}$. If $25 \%$ RHA and $50 \%$ PP are used in high foam content, the compressive strength decreased 1.6 times compared to the reference mixture.

If the PP ratio is $25 \%$, the 90 -day flexural strength generally increases. In particular, flexural strength was obtained as 7.6 MPa in mixtures without PP and with 25\% RHA content produced with low foam content. Using $12.5 \%$ RHA and $25 \%$ PP in high foam content, the flexural strength decreased 1.5 times compared to the reference mixture. While the use of $12.5 \%$ RHA in mixes with PP reduced the flexural strength, the flexural strength increased again with $25 \%$ RHA.

PP caused a decrease in early age strength due to pozzolanic activity. However, due to $\mathrm{RHA}^{\prime}$ sigh $\mathrm{SiO}_{2}$ content and specific surface area, strength increases were observed at an early age. As the foam content increased, the number of air bubbles raised, resulting in a loss of strength. But, since the increase in foam content improved workability, strength losses were minimal.

As seen in Fig 9A, as the porosity values of mixtures decrease, compressive strength increases. The $\mathrm{R}^{2}$ value between porosity and compressive strength was obtained as 0.75 . The porosity values of mixes with a compressive strength of $80 \mathrm{MPa}$ and above are less than $10 \%$. As the bulk density of cementbased composites reductions, compressive strength decreases. Cement-based composites with a bulk density value of $1667 \mathrm{~kg} / \mathrm{m}^{3}$ have a compressive strength of about $43 \mathrm{MPa}$. The bulk density of conventional concretes varies between $2400-2500 \mathrm{~kg} / \mathrm{m}^{3}$. In this study, dead loads will be reduced by about $30 \%$ owing to the composite developed. Also, although the density was reduced, high compressive strength of $43 \mathrm{MPa}$ was obtained. Figure $9 \mathrm{~b}$ shows that the $\mathrm{R}^{2}$ value between compressive and flexural 
strength is 0.79 . As the compressive strength of cement-based composites increases, the flexural strength also improves. The mixtures' flexural strength with a compressive strength of $80 \mathrm{MPa}$ has been determined as approximately $8 \mathrm{MPa}$. Also, a ratio of $1 / 9$ between compressive and flexural strength was observed.

Younes et al. have been determined that as the RHA content increases, the mortars' compressive strength increases. The strength increase is explained by RHA's activity in an alkaline environment and its amorphous structure (Younes et al. 2018). Kanthe et al. have been observed that RHA increases the compressive strength up to $10 \%$. RHA's pozzolanic properties and improving microstructure have increased its compressive strength (Kanthe et al. 2018). Mohseni et al. stated that up to $10 \%$ RHA increases the compressive strength. However, the use of higher rates of RHA reduced the compressive strength. The high rate of use of RHA prevents the formation of homogeneous hydrated microstructure. Also, the excessive silica content in the microstructure reduces the compressive strength (Mohseni et al. 2017). According to Karataş et al., the use of PP up to $15 \%$ increases the compressive and flexural strength. The development of strength provided by PP is explained by pozzolanic activity (Karataş et al. 2017). In the study of Zeyad et al., the use of PP up to $10 \%$ is to increase the 28 and 90 days compressive strength (Zeyad ve Almalki 2021). PP increases compressive strength due to its active $\mathrm{SiO}_{2}$ content and pozzolanic activity properties (Kiliç ve Sertabipo囚lu 2015). Lesovik et al. showed that foam concretes' compressive strength decreases as the foam content increases (Lesovik et al. 2020). Similar results were observed in foam concretes produced by Eltayeb et al. (Eltayeb et al. 2020).

\section{Drying shrinkage of cement-based composites}

As seen in Figure 10a, the mixtures' drying shrinkage values with $25 \mathrm{~kg} / \mathrm{m}^{3}$ foam content are generally below $2000 \times 10^{-6}$. The mixtures' drying shrinkage value without PP and RHA on the 120th day was obtained as $1444 \times 10^{-6}$. However, if $50 \%$ PP and $25 \%$ RHA were used, the mixtures' shrinkage value increased by $52.2 \%$. Generally, a $50 \%$ PP ratio increases the drying shrinkage values of mixes. The drying shrinkage values of these mixtures are $1900 \times 10^{-6}$ and above. The dry shrinkage values of the mixtures do not change much from the 56th day. If the PP ratio rises, the drying shrinkage values increase. Generally, the rise in the RHA rate increases the drying shrinkage values. The drying shrinkage value of cementbased composites using $25 \% \mathrm{RHA}$ is more than $1700 \times 10^{-6}$. The drying shrinkage value of mixtures where PP is not used but RHA is used $25 \%$ has increased 1.2 times compared to the reference mixture. Cement replacement materials used in mixtures with low foam content generally increased the drying shrinkage values. Cement-based composites occur $90 \%$ of the drying shrinkage in the first 56 days.

As seen in Fig 10b, as the foam content rises, the drying shrinkage value of mixtures also increases. Drying shrinkage values of mixtures with high foam content range from 1532-2512x10-6. In mixtures where PP is used at $50 \%$, the drying shrinkage value increased approximately 1.5 times compared to the reference mixture. The mixtures' shrinkage value using $25 \%$ RHA and 50\% PP was measured as $2515 \times 10^{-}$ 
${ }^{6}$ on the 120 th day. If the RHA is $12.5 \%$ in mixtures without PP, the drying shrinkage slightly decreases. Drying shrinkage slowed down from the 56th day in mixes with high foam content.

The $\mathrm{R}^{2}$ value between the 90 days compressive strength and 120 days drying shrinkage values of the mixtures was 0.78 (Fig 11). As the compressive strength of cement-based composites increases, the drying shrinkage values decrease. In particular, 120-day shrinkage values of mixtures with compressive strength above $80 \mathrm{MPa}$ are below $1400 \times 10^{-6}$. The drying shrinkage value of mixtures with a compressive strength of $40 \mathrm{MPa}$ was measured as approximately $2500 \times 10^{-6}$. While the increase in PP ratio decreased the compressive strength, it increased the drying shrinkage values. A slightly low correlation $\left(R^{2}=0.61\right)$ was observed between drying shrinkage and porosity. As the apparent porosity values of cement-based composites rise, the drying shrinkage values generally increase. It has been observed that mixtures with a higher porosity ratio cause more shrinkage. Especially as the foam content increases, the number of air bubbles in the mix increases. As the porosity rate increases, the evaporation of the water in the macro and microstructure becomes easier. Thus, more shrinkage will occur by increasing the rate of water loss in cement-based composites. Also, the use of $50 \%$ PP and $25 \%$ RHA generally reduces workability. Porosity values of mixtures increase as a result of the decrease in workability. Therefore, more drying shrinkage was observed in mixtures with $50 \%$ PP content. A similar effect occurred with mixes using $25 \%$ RHA.

Chatveera and Lertwattanaruk observed that the use of 20\% RHA slightly increased the drying shrinkage. It was emphasized that drying shrinkage is related to the paste volume and capillary space structure (Chatveera ve Lertwattanaruk 2011). Sadrmomtazi et al. stated that, unlike silica fume, rice husk ash causes an increased drying shrinkage (Sadrmomtazi et al. 2012). Kızılkanat et al. have determined that as the PP content increases, the mortars' drying shrinkage decreases (Kizilkanat et al. 2016). Özbay et al. stated that non-hydrated pozzolana particles behave like fine aggregate to reduce shrinkage deformation. Also, it has been determined that the shrinkage decreases as the amount of evaporable water reduction due to the pozzolanic reaction (Özbay et al. 2012). In this study, as the PP ratio increased, the workability decreased, so the capillary void content increased. As a result of the rises in the capillary void ratio, the shrinkage values increased. Also, RHA consumed more water during hydration than PP due to its high specific surface area. The participation of RHA in hydration at an early age has also been effective in this process. Since PP did not complete pozzolanic activity during the 7-day curing period, it did not make a positive contribution to the microstructure. Therefore, as the PP ratio increased, the shrinkage values raised. Nambiar and Ramamurthy noted that as the foam content increased, the shrinkage decreased because the paste volume decreased (Nambiar ve Ramamurthy 2009). But in this study, the aggregate volume decreases as the foam content increases. Thus, the drying shrinkage values of mixtures have increased.

\section{Sorptivity of Cement-Based Composites}

Time-dependent water penetration depths of mixtures with $12.5 \mathrm{~kg} / \mathrm{m}^{3}$ foam content are given in Figure 12a. The lowest water penetration depth, $0.20 \mathrm{~mm}$, was obtained in a mix without PP and $12.5 \% \mathrm{RHA}$. 
The water penetration depth of the reference mixture was measured at approximately $0.60 \mathrm{~mm}$. If RHA is used at a rate of $12.5 \%$, the depth of water penetration is reduced by $66 \%$. The highest water penetration depth $(6.1 \mathrm{~mm})$ was observed in mixtures using 25\% RHA and 50\% PP. The water penetration depth has increased approximately five times compared to the reference mixture. As the PP content increases, the mixtures' workability decreases, and the water penetration depth has increased. Especially, the water penetration depth of 50\% PP content mixtures exceeded $2 \mathrm{~mm}$. The increase in RHA content generally reduced the depth of water penetration.

Figure $12 \mathrm{~b}$ shows that as the mixtures' foam content increases, the depth of water penetration increases. Water penetration depths of mixtures with a foam content of $25 \mathrm{~kg} / \mathrm{m}^{3}$ range from $1.3-7.2 \mathrm{~mm}$. In particular, cement-based composites with a PP ratio of $50 \%$ have a water penetration depth of more than $5 \mathrm{~mm}$. The highest water penetration depth $(7.2 \mathrm{~mm})$ was observed in mixtures containing $50 \%$ PP and $12.5 \%$ RHA. Water penetration depth increased by $243 \%$ compared to the reference mixture. The lowest water penetration depth $(1.3 \mathrm{~mm})$ was again obtained in mixes with $0 \% \mathrm{PP}$ and $12.5 \% \mathrm{RHA}$ content. If the $\mathrm{PP}$ ratio is low, RHA's use at $25 \%$ reduces water penetration depth. It is observed that mixtures without PP and RHA of $12.5-25 \%$ show similar properties. Increasing the number of air bubbles in the mix increases the depth of water penetration. Usually, mixes with low workability have excessive water penetration depths. It has been determined that RHA is more effective in reducing the depth of water penetration.

As seen in Figure 13a, as the mixtures' compressive strength increases, water penetration depth decreases. Water penetration depths of mixes with compressive strength above $70 \mathrm{MPa}$ are less than $1.50 \mathrm{~mm}$. The compressive strength increases as a result of the reduction of capillary voids. Increasing the ratio of RHA with high specific surface area generally reduces capillary voids. As the water absorption values of the mixtures increase, the water penetration depth increases. Figure $13 \mathrm{~b}$ shows that the drying shrinkage values increase as the water penetration depth increases. For drying shrinkage, the amount of capillary void and network is an essential factor. Because as the capillary void ratio increases, the evaporation of the macro and microstructure water becomes easier. Firstly, in cement-based composites, the water in the capillary voids and the gel (CSH) water evaporates. As RHA usually reduces capillary voids, it also reduced drying shrinkage. RHA absorbs some of the water at the mixing stage. However, it releases the absorbed water during the hydration phase. This effect improves the microstructure of cement-based composites. Therefore, the capillary void ratio of RHA-containing mixtures is less.

Patel and Sha used different ratios of RHA in geopolymer production. The use of 5\% RHA reduced the capillarity coefficients of the geopolymer mixtures. It has been stated that the permeability depends on the structure of the pores and the size distribution. The absorption of water depends on the continuity of the voids. The gels formed by hydration reduce the permeability by closing these voids. Also, it has been determined that RHA cannot react if used at a high rate and creates a more porous microstructure (Patel ve Shah 2018). Kameshwar et al. have determined that with $20 \%$ RHA in cement mortars, water penetration depth decreases. They stated that pozzolanic activity was effective in reducing the depth of water penetration (Kameshwar et al. 2020). Similar results were obtained in high strength concretes made by Priya et al. (Shanmuga Priya et al. 2021). Kabay et al. determined that the use of 10\% PP in cement 
mortars effectively reduces capillarity. It has been observed that PP reduces capillary by filling capillary voids (Kabay et al. 2015). Panesar has produced foam concretes using different foaming agents. As the foam content increased, the capillarity coefficients of foam concrete increased (Panesar 2013). Nambiar et al. reported that capillarity is affected by the number of pores during capillary water absorption. If the pores are connected, water absorption is high, but water absorption decreases in discontinuous pores (Nambiar ve Ramamurthy 2007). In the study conducted by Ahmad and Chen, foam concretes' capillarity increased as the foam volume increased (Ahmad ve Chen 2019). In this study, the fact that the pores are very close to each other in mixtures with a high foam content affected capillarity. Discontinuous porosity could not be achieved because the pores were close to each other. As a result, the depth of water penetration increased as the foam content increased.

\section{Sulfate Resistance of Cement-Based Composites}

Figure 14a shows the time-dependent expansion of mixtures with a foam content of $12.5 \mathrm{~kg} / \mathrm{m}^{3}$. The reference mixture (\% PP- $0 \% \mathrm{RHA}$ ) expansion on the 150 th day was measured as $286 \times 10^{-6}$. In mixtures with $\mathrm{RHA}$ of $12.5 \%$ and $0 \% \mathrm{PP}$, the expansion value decreased to $273 \times 10^{-6}$. The expansion value of the mixes using $50 \%$ PP exceeded the value of $350 \times 10^{-6}$. In particular, the mixtures' expansion value using $25 \% \mathrm{RH}$ and $50 \% \mathrm{PP}$ increased $82 \%$ compared to the reference mixture. As a result of the increase in PP ratio, the expansion of the mixtures raises. Mixtures without PP but containing RHA have less expansion than the reference mixture. It has been observed that RHA is more effective in reducing sulfate-based expansions.

The expansion of mixtures with high foam content $\left(25 \mathrm{~kg} / \mathrm{m}^{3}\right)$ is generally increased. However, the expansion amount of mixtures without RHA is less than mixtures produced with low foam content. The high workability of these mixtures has made the mixture more homogeneous. This effect has reduced the sulfate-based expansions. When using $12.5 \%$ of RHA in mixes without PP, the expansion decreased by $11 \%$ compared to the reference mixture. The expansion values of mixes with high foam content range from $255-655 \times 10^{-6}$. In high foam content, the maximum expansion $\left(655 \times 10^{-6}\right)$ was observed in mixtures with $12.5 \%$ RHA and 50\% PP. The expansion value increased 2.3 times compared to the reference mixture.

As seen in Figure 15a, the $\mathrm{R}^{2}$ value between compressive strength and expansion was determined as 0.89. As the compressive strength of cement-based composites increases, the expansion caused by sulfate decreases. Mixtures with low compressive strength before exposure to the sulfate solution suffered more damage in this process. It was also observed that as the apparent porosity of the mixtures increased, its expansion raised. It is seen that the void structure is crucial in sulfate-based expansions. Since the workability affects the void structure, mixtures containing 50\% PP made more expansion.

As seen in Figure 15b, the mixtures' expansion raises as the depth of water penetration and water absorption rate increase. An increase in the foam content caused the voids to be close to each other. As a result of this effect, the water penetration depth of the mixtures has increased. As the void ratio increases, the entry of sulfate ions into cement-based composites is easier. If PP is used by $50 \%$, porosity increases 
as workability decreases. Therefore, because of the high porosity in 50\% PP mixtures, the expansions occurred too much. $\mathrm{CH}$ was not fully consumed since the pozzolanic activity was not completed before the mixes' sulfate effect. Thus, the use of high amounts of PP decreased the compressive strength and increased the sulfate damage. The slower pozzolanic activity of PP compared to RHA affected the sulfate resistance negatively. In cement-based composites to be produced with PP, attention should be paid to the curing process to increase the resistance against the sulfate effect.

Chindaprasirt et al. have produced cement mortars using up to 40\% RHA. They determined that as the RHA content increased, the expansions decreased (Chindaprasirt et al. 2007). It was emphasized that the $\mathrm{Ca} / \mathrm{Si}$ ratio of paste is crucial in terms of sulfate resistance. It was observed that silica gel was formed, protecting the $\mathrm{CSH}$ gel at a low Ca/Si ratio (Shi ve Stegemann 2000). Kabay et al. observed that the magnesium sulfate resistance of concrete increased with the use of PP. However, these concretes have constant slump values (Kabay et al. 2015). In this study, as the PP ratio of the mixtures increased, the flow diameters decreased. It was determined that the relationship between workability and void structure is essential in terms of sulfate resistance. There are no comprehensive studies in the literature showing the resistance of foam concrete against the sulfate effect. But cement-based composites with high compressive strength of 91 days were less affected by the sulfate effect.

\section{Acid Resistance of Cement-Based Composites}

The mass changes of mixtures with $12.5 \mathrm{~kg} / \mathrm{m}^{3}$ foam content under the effect of $\mathrm{H}_{2} \mathrm{SO}_{4}$ are given in Figure 16a. The reference mixture's mass increased by approximately $3.1 \%$ due to the exposure to $\mathrm{H} 2 \mathrm{SO} 4$ for 150 days. A similar mass gain (\%1.7) was observed in mixes with 12.5\% RHA and without PP. In cement-based composites, the highest mass loss (\%5.2) occurred in mixtures containing 25\% RHA and $50 \%$ PP. The mass loss of mixtures using $25 \%$ RHA is more than $3 \%$. A similar effect was observed with cement-based composites using 50\% PP. The mixtures' mass loss without RHA and 25\% PP on the 150th day were measured as $2.0 \%$. The mixtures' mass loss containing $12.5 \%$ RHA and $25 \%$ PP was determined as $1.8 \%$. Generally, using a high ratio of cement replacement materials increases weight loss under the effect of $\mathrm{H}_{2} \mathrm{SO}_{4}$.

The mass losses of mixtures produced with high foam content are similar to those made with low foam content (Fig 16b). The increase in foam content has relatively increased the mass losses of mixtures. The mass gain occurred in the reference mixture, exposed to $\mathrm{H}_{2} \mathrm{SO}_{4}$ for 150 days, as with the low foam content. The mass of the reference mixture increased by $4 \%$ with the effect of $\mathrm{H}_{2} \mathrm{SO}_{4}$. The mass gain was determined as $1.7 \%$ in mixtures with $12.5 \%$ RHA and without PP. The use of $50 \%$ PP in mixes usually increases mass loss. In particular, the mass loss of $25 \%$ RHA and $50 \%$ PP mixtures on the 150 th day was measured as $6.5 \%$. Since the increase in PP ratio generally decreases the compressive strength, mass loss increased with $\mathrm{H}_{2} \mathrm{SO}_{4}$. If cement replacement materials are used in combination against the $\mathrm{H}_{2} \mathrm{SO}_{4}$ effect, it may be more effective to use low rates. 
Figure 17 shows that the $\mathrm{R}^{2}$ value between the 91 -day compressive strength and mass change is low. However, it is seen that the mass loss is less in mixtures with high compressive strength for 91 days. The mass gain occurred in mixtures with reference and 12.5\% RHA content. The compressive strength of these mixtures is over $70 \mathrm{MPa}$.

In the study conducted by Chang et al., the mass gain was also observed in concretes exposed to $1 \%$ $\mathrm{H}_{2} \mathrm{SO}_{4}$. The mass gain was explained by continued hydration of cement, gypsum formation, and an increase in the sample amount of water absorbed (Chang et al. 2005). Gypsum formation was determined on the surface of cement-based composites exposed to the $\mathrm{H}_{2} \mathrm{SO}_{4}$ effect. Since the gypsum formed on the surface reduces the permeability slightly, it can positively contribute to acid resistance (Barbhuiya ve Kumala 2017).

Figure 18a shows the mass loss of mixtures with a foam content of $12.5 \mathrm{~kg} / \mathrm{m} 3$ exposed to $\mathrm{HCl}$. Mass losses of cement-based composites range from 1.4-6.4\%. The reference mixture's mass loss with a high $\mathrm{CH}$ content on the 150 th day was determined as $6.4 \%$. The mixtures' mass loss using $25 \%$ RHA and $50 \%$ PP was reduced by $78.1 \%$ compared to the reference mixture. It has been determined that the $\mathrm{CH}$ content is significant for cement-based composites exposed to $\mathrm{HCl}$. Using the $\mathrm{RHA}$ content of $25 \%$ in mixes with low foam content effectively reduced mass loss.

The increase in the foam content used in the production of cement-based composites generally increases the mass losses. But, the increase in foam content has reduced the degree of damage in some mixtures. In mixtures with $12.5 \%$ RHA and $25 \%$ PP, $2.2 \%$ weight loss occurred at low foam content, while a weight loss of $1.1 \%$ in high foam content was measured. Since the mixtures' workability improved with the increase in foam content, a more homogeneous matrix was obtained. As a result, the resistance of the mixes against $\mathrm{HCl}$ has increased. The mixtures' mass loss using $12.5 \% \mathrm{RHA}$ and $50 \% \mathrm{PP}$ was decreased by $89.2 \%$ compared to the reference mixture. The high rate of use of cement replacement materials generally reduced the mass loss below $2 \%$.

Figure 19 shows that water absorption or depth of water penetration does not affect weight loss. For example; The weight loss of a mixture with a water absorption rate of $13.1 \%$ was measured as $1.1 \%$. The water penetration depth of the same mixture was determined as $7.7 \mathrm{~mm}$. In a mix with a water penetration depth of $2.1 \mathrm{~mm}$, the weight loss was measured as $10.1 \%$. Thus, $\mathrm{CH}$ content is crucial in cement-based composites exposed to the $\mathrm{HCl}$ effect. Cement replacement materials should be consumed in $\mathrm{CH}$ in the paste by using high proportions.

Meddah et al. reduced mass loss by using 10\% RHA in concretes exposed to 3.5\% $\mathrm{HCl}$ (Meddah et al. 2020). In the study conducted by Khan et al., concretes' acid resistance was increased with RHA use (Khan et al. 2012). Also, secondary CSH gels formed as a result of using natural pozzolans increase acid resistance. Cement replacement materials improve microstructure is an essential factor for acid resistance (Ghrici et al. 2007). Joshaghani and Moeini increased the $\mathrm{H}_{2} \mathrm{SO}_{4}(\% 1$ ) resistance by using up to $30 \%$ RHA in cement mortars (Joshaghani ve Moeini 2018). In the literature review, the resistance of 
foam concretes against $\mathrm{H} 2 \mathrm{SO} 4$ or $\mathrm{HCl}$ effect was not observed. However, in this study, it was determined that the mixtures' acid resistance would be increased by using RHA or PP in optimum proportions.

\section{Freezing and Thawing Resistance of Cement-Based Composites}

Figure 20a shows the relative dynamic elasticity modules and compressive strengths after $100 \mathrm{~F}-\mathrm{T}$ cycles. It was observed that the RDEM value (\%108.9) of the reference mixture increased at low foam content. A similar effect was observed with the mixture without RHA but with $50 \%$ PP. The mixtures' RDEM value using $12.5 \%$ RHA and $50 \%$ PP was also measured as $103.6 \%$. Although the mixture using $12.5 \%$ RHA (without PP) has a high 91 days-compressive strength, the RDEM value was determined as $86 \%$ after $100 \mathrm{~F}-\mathrm{T}$. Especially, lower RDEM values were obtained in the mixtures when the PP ratio was $25 \%$. RDEM value using 25\% PP and 25\% RHA decreased by $34.3 \%$ compared to the reference mixture. The increase in PP content in mixtures using 25\% RHA significantly decreased RDEM values. However, if $50 \%$ of PP is used in mixes with $12.5 \%$ RHA, the RDEM value decreased by $4.9 \%$ compared to the reference mixture.

In high foam content, the increase in PP ratio in mixtures without RHA enhances the RDEM values. RDEM value of the reference mixture was obtained as $86.5 \%$ if the foam content was $25 \mathrm{~kg} / \mathrm{m}^{3}$. RDEM values of mixtures using $25 \%$ and $50 \%$ PP increased by $4.8-11.3 \%$ after $100 \mathrm{~F}-\mathrm{T}$. RDEM values of mixtures using $12.5 \%$ RHA decreased more than other mixes. RDEM value using $12.5 \%$ RHA and $50 \%$ PP decreased by $11.7 \%$ compared to the reference mixture. RDEM values were observed very close to each other in mixes using $25 \%$ RHA.

The compressive strength of cement-based composites produced with low foam content after $100 \mathrm{~F}-\mathrm{T}$ ranges from 83.6-48.1 $\mathrm{MPa}$. The increase in RHA content in mixtures with 50\% PP reduces the compressive strength after FT. The mixtures' compressive strength using 50\% PP and 25\% RHA has decreased by $42.2 \%$ compared to the reference mixture. Generally, the compressive strength has decreased with the increase in PP and RHA content. But, despite the 100 FT effect, the compressive strength of $70 \mathrm{MPa}$ and above was observed in cement-based composites.

In mixtures with high foam content, compressive strengths between 77.6-44.0 MPa were obtained after $100 \mathrm{FT}$. If $12.5 \% \mathrm{RHA}$ is used in mixes without PP, the compressive strength increased by $13 \%$ compared to the reference mixture. If $12.5 \% \mathrm{RHA}$ is used in mixes with PP, the compressive strength decreases. The lowest compressive strength (44.0 MPa) after $100 \mathrm{FT}$ was observed in mixtures with $50 \% \mathrm{PP}$ and $25 \%$ RHA. Also, the increase in foam content generally reduced the compressive strength after $100 \mathrm{FT}$.

In Figure 20b, RDEM and compressive strengths of cement-based composites are given after $200 \mathrm{FT}$. The increase in the number of cycles led to a decrease in RDEM and compressive strength. RDEM value of the reference mixture was obtained as $66 \%$ in mixtures with low foam content. In using $25 \%$ PP in mixes without RHA, the RDEM value increased by $24.3 \%$ compared to the reference mixture. After $200 \mathrm{FT}$, the RDEM value of mixtures with $25 \%$ RHA and $50 \%$ PP was $48.1 \%$. RDEM value decreased by $27.2 \%$ compared to the reference mixture. 
The increase in PP ratio in high foam content generally decreased RDEM values. RDEM value of the reference mixture was determined as $74.4 \%$. RDEM value increased by $18.9 \%$ in $12.5 \%$ RHA and $0 \% \mathrm{PP}$ mixtures compared to the reference mixture. RDEM value decreased by $39.5 \%$ in $25 \%$ RHA and $50 \%$ PP mixtures compared to the reference mixture.

As the number of cycles exposed to cement-based composites increased, compressive strength decreased. The compressive strength of mixtures with low foam content varies between $64.6-25.8 \mathrm{MPa}$ after $200 \mathrm{FT}$. After $200 \mathrm{FT}$, compressive strengths of $60 \mathrm{MPa}$ and above were obtained in mixes without PP. Increasing RHA content in mixtures produced with PP generally decreases the compressive strength. The mixtures' compressive strength produced with 50\% PP and 25\% RHA decreased by 58.5\% compared to the reference mixture.

Compressive strength of mixtures with high foam content after $200 \mathrm{FT}$ ranges from 25.5-62.4 MPa. An increase in PP and RHA content generally decreases compressive strength. However, in mixtures with $12.5 \%$ RHA and $25 \%$ PP, the compressive strength of approximately $50 \mathrm{MPa}$ was obtained after $200 \mathrm{FT}$. Although cement-based composites were exposed to $200 \mathrm{FT}$, compressive strengths of $50 \mathrm{MPa}$ and above were observed. Relatively lower compressive strength has been obtained in cement-based composites produced with $50 \%$ PP.

As shown in Figure 21, a low correlation was obtained between the water penetration depth and RDEM values of cement-based composites. But, RDEM values tend to decrease as the depth of water penetration of mixtures increases. It seems that the capillary void structure has little effect on FT. It has been determined that mixtures with a high depth of water penetration suffer more damage.

Yang et al. increased freeze-thaw resistance by using RHA in cement-based composites. They stated that RHA increases the freeze-thaw resistance by reducing the mixtures' air content (Yang et al. 2016). It has been noted that the stress density resulting from freezing is closely related to porosity (Netinger et al. 2014). Tikalsky et al. have been observed that its properties, such as compressive strength, initial water penetration depth, and water absorption, are very effective in frost resistance (Tikalsky et al. 2004). Similar results were observed within this study. Cement-based composites with high initial compressive strength were less affected by the freeze-thaw effect. After $100 \mathrm{FT}$, there was no loss of strength in some mixtures, such as the reference mixture. In fact, it was observed that RDEM values increased after $100 \mathrm{FT}$. The continuation of hydration with freeze-thaw can explain this effect. Especially in low cycles, the continuation of pozzolanic activity has decreased the strength losses. There are other studies in the literature that RDEM values increase due to the F-T effect (Nehdi ve Bassuoni 2008; Gheni et al. 2017). In this study, compressive strengths of $50 \mathrm{MPa}$ and above were obtained by using $50 \%$ PP due to $200 \mathrm{FT}$. Due to $25 \%$ RHA content in the mixtures, compressive strengths of $45 \mathrm{MPa}$ and above were observed after $200 \mathrm{FT}$.

\section{Microstructure}


The microstructure properties of cement-based composites exposed to sodium sulfate are given in Figure 22.

As seen in Figure 22 (a-c), structures such as ettringite and gypsum are observed in mixtures exposed to sodium sulfate. It is seen in Figure 22c that ettringite diameters are thinner (more needlelike). Although natural and artificial pozzolans were used in the mixtures, the presence of ettringite was determined.

As shown in Figures 23 a and b, micro cracks were observed in the matrix of cement-based composites. But it was also found that damage did not occur in some areas of the matrix. In Figure 23b, it was observed that the matrix changed into a porous (spongy) structure. Sheet-like crystals are observed in Figure 23c.

In Figures $24 \mathrm{a}$ and $\mathrm{b}$, it was seen that gypsum was densely formed within the matrix. It is also observed in spongy (porous) structures as well as cracks in the matrix. Ettringite crystals were found in some parts of the matrix by the effect of sulfuric acid (Fig. 24c).

\section{Conclusions}

Increasing RHA and PP content decreases the flow diameters of the mixtures. The porous structure of RHA and PP usually reduces workability. Since RHA and PP in the mixtures increase the paste volume, the workability has improved compared to the reference mixture. The increase in foam content improved the flow diameter of the mixtures. The air-entraining property of the foam has improved the workability of the mixtures.

When using RHA and PP, apparent porosity and water absorption values increased compared to the reference mixture. Increasing PP content in mixtures raises water absorption and visible porosity. When $25 \%$ RHA was used in the mixtures, apparent porosity values decreased more than $12.5 \%$ RHA. The increase in foam content rose the water absorption and apparent porosity values. The densities of the mixtures vary between $1666-2205 \mathrm{~kg} / \mathrm{m}^{3}$. It has been determined that cement-based composites can be used in structural and semi-structural elements. As the foam and PP content increased, the density of the mixtures decreased.

The use of $12.5 \%$ RHA in the mixtures increased early age strengths. As the PP content used in the mixtures increased, 91-day compressive strength decreased. Compressive strengths of $40 \mathrm{MPa}$ and above were observed in mixtures using 50\% PP. Compressive strengths of $45 \mathrm{MPa}$ and above were observed in mixtures using $25 \%$ RHA. Increasing the foam content increases the mixtures' apparent porosity values, and so, compressive strength decreases. Despite this, the mixture's compressive strength with a density of $1666 \mathrm{~kg} / \mathrm{m}^{3}$ was determined as $42.1 \mathrm{MPa}$.

The use of $50 \% \mathrm{PP}$ in the mixes generally increases the drying shrinkage. Using $12.5 \% \mathrm{RHA}$ (without using PP) reduces drying shrinkage compared to the reference mixture. Drying shrinkage of cementbased composites produced with high foam content $\left(25 \mathrm{~kg} / \mathrm{m}^{3}\right)$ has increased. As the mixtures' apparent 
porosity increases, the evaporation of the water in the paste becomes easier. As the compressive strength of cement-based composites increases, the drying shrinkage decreases.

Water penetration depths of mixtures using 50\% PP have increased. Using RHA in mixtures was more effective than PP in reducing the depth of water penetration. Since the increase in PP content reduces the workability, the depth of water penetration has increased. As a result of the increase in the foam content, the air bubbles converged. Thus, as the foam content increased, the depth of water penetration increased.

As the apparent porosity of cement-based composites increases, sulfate-induced expansions also increase. It has been observed that mixtures with high compressive strength are less affected by sulfate. Since the increase in the foam content raises the permeability, the sulfate-related expansions have increased. In particular, the expansion of $50 \%$ PP mixtures was slightly higher. If PP is used at a low rate, $\mathrm{RHA}$ reduced the expansion of the mixtures.

Mass loss decreases as PP and RHA content increases in mixtures exposed to $\mathrm{HCl}$. It has been observed that the $\mathrm{CH}$ content is significant in mixes exposed to $\mathrm{HCl}$. As the content of cement replacement materials increases, the $\mathrm{CH}$ content in the paste decreases. This effect increases the resistance of cement-based composites against $\mathrm{HCl}$. The opposite situation was determined for mixtures exposed to the $\mathrm{H}_{2} \mathrm{SO}_{4}$ effect. Impermeability is important in mixtures exposed to $\mathrm{H}_{2} \mathrm{SO}_{4}$.

It has been observed that the initial strength is significant in cement-based composites exposed to FT. RDEM values of some cement-based composites increased after $100 \mathrm{FT}$. As hydration continues in low FT cycles, sometimes RDEM and compressive strength can increase. Compressive strengths of $20 \mathrm{MPa}$ and above were obtained in cement-based composites exposed to $200 \mathrm{FT}$. Mixtures using $50 \%$ PP were more affected by the 200 FT cycle. It is appropriate to use $12.5 \%$ and $25 \%$ RHA without using PP in the mixtures.

The microstructure investigations determined that sodium sulfate and sulfuric acid caused more ettringite and gypsum formation. It was determined that a porous (spongy) structure was formed in the matrix due to the effects of hydrochloric and sulfuric acids. It has been observed that hydrochloric acid usually generates micro-cracks in the matrix.

In this study, it has been seen that RHA is organic waste, is suitable to use up to $25 \%$. But, if $25 \% \mathrm{RHA}$ is used in mixtures, the PP should be a maximum of $25 \%$. The use of PP at a rate of $50 \%$ in mixes with $25 \%$ RHA decreases the workability. Thus the performance of cement-based composites is negatively affected. If $50 \%$ PP is used, it is more appropriate not to use RHA. As a result of the experimental study, it has been seen that sustainable cement-based composites with RHA can be produced.

\section{Declarations}

\section{Acknowledgement}


This study was supported by the Scientific Research Projects Coordination Unit of Atatürk University. The experimental study was carried out with the project coded FHD20218920.

\section{Compliance with ethical standards}

Competing interest: The authors declare that they have no competing interests.

Ethics approval and consent to participate: Not applicable

Consent for publication: Not applicable

Authors' contributions: Gokhan Kaplan; Contributed to the writing of the article and the literature review. Mohamed A.Salem Elmekahal; Perofrmed the experiments and analyse the results.

Availability of data and materials: Data and material are available for research purpose and for reference.

\section{References}

Abbas S, Kazmi SMS, Munir MJ (2017) Potential of rice husk ash for mitigating the alkali-silica reaction in mortar bars incorporating reactive aggregates. Constr Build Mater. https://doi.org/10.1016/j.conbuildmat.2016.11.126

Abdollahnejad Z, Pacheco-Torgal F, de Aguiar JB (2015) Development of Foam One-Part Geopolymers with Enhanced Thermal Insulation Performance and Low Carbon Dioxide Emissions. Adv Mater Res. https://doi.org/10.4028/www.scientific.net/amr.1129.565

Ahmad MR, Chen B (2019) Experimental research on the performance of lightweight concrete containing foam and expanded clay aggregate. Compos Part B Eng.

https://doi.org/10.1016/j.compositesb.2019.04.025

Al-Khalaf MN, Yousif HA (1984) Use of rice husk ash in concrete. Int J Cem Compos Light Concr. https://doi.org/10.1016/0262-5075(84)90019-8

Alnahhal AM, Alengaram UJ, Yusoff S et al (2021) Synthesis of sustainable lightweight foamed concrete using palm oil fuel ash as a cement replacement material. J Build Eng.

https://doi.org/10.1016/j.jobe.2020.102047

American Society of Testing and Materials (2016) C597-16 Standard Test Method for Pulse Velocity Through Concrete. ASTM Int

Amran YHM, Farzadnia N, Ali AAA (2015) Properties and applications of foamed concrete; A review. Constr. Build. Mater

ASTM (2013) C1437 - Standard test method for flow of hydraulic cement mortar 
ASTM C 1585-04 (2004) Standard test method for measurement of rate of absorption of water by hydraulic-cement concretes. ASTM Int

ASTM C 596-01 (2001) Standard Test Method for Drying Shrinkage of Mortar Containing Hydraulic Cement. Annu B ASTM Stand. https://doi.org/10.1520/C0596-18.2

ASTM C1012 (2004) ASTM C1012-04: StandardStandard Test Method for Length Change of HydraulicCement Mortars Exposed to a Sulfate Solution. Annu B ASTM Stand

ASTM C348 (1998) Standard Test Method for Flexural Strength of Hydraulic-Cement Mortars. Annu B ASTM Stand

ASTM C349 (2002) Standard test method for compressive strength of hydraulic-cement mortars (Using portions of prisms broken in flexure). ASTM Int

ASTM C642-13 (2013) Standard test method for density, absorption, and voids in hardened concrete, ASTM International. ASTM Int

Astm C/C666M (2003) Standard Test Method for Resistance of Concrete to Rapid Freezing and Thawing. ASTM Int West Conshohocken, PA. https://doi.org/10.1520/C0666

ASTM International ASTM C1152 / C1152M - 20 Standard Test Method for Acid-Soluble Chloride in Mortar and Concrete

Muhit B, Ahmed SS MMA and Muhit MTR, Ahmed IB SS, et al (2013) Effects of Silica Fume and Fly Ash as Partial Replacement of Cement on Water Permeability and Strength of High Performance Concrete. Aetace 2013

Barbhuiya S, Kumala D (2017) Behaviour of a sustainable concrete in acidic environment. Sustain. https://doi.org/10.3390/su9091556

Bayraktar OY (2021) Possibilities of disposing silica fume and waste glass powder, which are environmental wastes, by using as a substitute for Portland cement. Environ Sci Pollut Res. https://doi.org/10.1007/s11356-020-12195-9

Bekem Kara İ, Durmuş ÖF (2019) Effect of nano silica on cement mortars containing micro silica. Chall J Concr Res Lett. https://doi.org/10.20528/cjcrl.2019.02.003

Bhanumathidas N, kumar P M (2001) Concrete mixtures made with ternary blended cements containing fly ash and rice husk ash. Int Concr Abstr Portal

Chandni TJ, Anand KB (2018) Utilization of recycled waste as filler in foam concrete. J Build Eng. https://doi.org/10.1016/j.jobe.2018.04.032 
Chang ZT, Song XJ, Munn R, Marosszeky M (2005) Using limestone aggregates and different cements for enhancing resistance of concrete to sulphuric acid attack. Cem Concr Res 35:1486-1494. https://doi.org/10.1016/j.cemconres.2005.03.006

Chatveera B, Lertwattanaruk P (2011) Durability of conventional concretes containing black rice husk ash. J Environ Manage. https://doi.org/10.1016/j.jenvman.2010.08.007

Chindaprasirt P, Kanchanda P, Sathonsaowaphak A, Cao HT (2007) Sulfate resistance of blended cements containing fly ash and rice husk ash. Constr Build Mater 21:1356-1361.

https://doi.org/10.1016/j.conbuildmat.2005.10.005

Chindaprasirt P, Rukzon S (2008) Strength, porosity and corrosion resistance of ternary blend Portland cement, rice husk ash and fly ash mortar. Constr Build Mater.

https://doi.org/10.1016/j.conbuildmat.2007.06.010

Chung SY, Abd Elrahman M, Kim JS et al (2019) Comparison of lightweight aggregate and foamed concrete with the same density level using image-based characterizations. Constr Build Mater. https://doi.org/10.1016/j.conbuildmat.2019.03.270

Danish A, Mosaberpanah MA (2021) Influence of cenospheres and fly ash on the mechanical and durability properties of high-performance cement mortar under different curing regimes. Constr Build Mater 279:122458. https://doi.org/10.1016/j.conbuildmat.2021.122458

De Gutiérrez RM, Díaz LN, Delvasto S (2005) Effect of pozzolans on the performance of fiber-reinforced mortars. Cement and Concrete Composites, Içinde

De Souza Rodrigues C, Ghavami K, Stroeven P (2006) Porosity and water permeability of rice husk ashblended cement composites reinforced with bamboo pulp. Journal of Materials Science, lçinde

Eltayeb E, Ma X, Zhuge Y et al (2020) Influence of rubber particles on the properties of foam concrete. J Build Eng. https://doi.org/10.1016/j.jobe.2020.101217

Falliano D, De Domenico D, Ricciardi G, Gugliandolo E (2018a) Experimental investigation on the compressive strength of foamed concrete: Effect of curing conditions, cement type, foaming agent and dry density. Constr Build Mater. https://doi.org/10.1016/j.conbuildmat.2017.12.241

Falliano D, De Domenico D, Ricciardi G, Gugliandolo E (2018b) Key factors affecting the compressive strength of foamed concrete. Içinde: IOP Conference Series: Materials Science and Engineering

FAO (2018) FAO Rice Market Monitor

Ganesan K, Rajagopal K, Thangavel K (2008) Rice husk ash blended cement: Assessment of optimal level of replacement for strength and permeability properties of concrete. Constr Build Mater. https://doi.org/10.1016/j.conbuildmat.2007.06.011 
Gheni AA, ElGawady MA, Myers JJ (2017) Mechanical characterization of concrete masonry units manufactured with crumb rubber aggregate. ACI Mater J. https://doi.org/10.14359/51689482

Ghrici M, Kenai S, Said-Mansour M (2007) Mechanical properties and durability of mortar and concrete containing natural pozzolana and limestone blended cements. Cem Concr Compos.

https://doi.org/10.1016/j.cemconcomp.2007.04.009

Givi AN, Rashid SA, Aziz FNA, Salleh MAM (2010) Assessment of the effects of rice husk ash particle size on strength, water permeability and workability of binary blended concrete. Constr Build Mater. https://doi.org/10.1016/j.conbuildmat.2010.04.045

Gowri R, Anand KB (2018) Utilization of fly ash and ultrafine GGBS for higher strength foam concrete. Içinde: IOP Conference Series: Materials Science and Engineering

Granata MF (2015) Pumice powder as filler of self-compacting concrete. Constr Build Mater. https://doi.org/10.1016/j.conbuildmat.2015.08.040

Gupta S, Kua HW, Koh HJ (2018) Application of biochar from food and wood waste as green admixture for cement mortar. Sci Total Environ. https://doi.org/10.1016/j.scitotenv.2017.11.044

Gursel AP, Maryman H, Ostertag C (2016) A life-cycle approach to environmental, mechanical, and durability properties of "green" concrete mixes with rice husk ash. J Clean Prod. https://doi.org/10.1016/j.jclepro.2015.06.029

Hamidah MS, Azmi I, Ruslan MRA et al (2005) Optimisation of foamed concrete mix of different sandcement ratio and curing conditions. Içinde: Proceedings of the International Conference on the Use of Foamed Concrete in Construction

Hossain KMA (2003) Blended cement using volcanic ash and pumice. Cem Concr Res. https://doi.org/10.1016/S0008-8846(03)00127-3

Hossain T, Sarker SK, Basak BC (2011) Utilization potential of rice husk ash as a construction material in rural areas. J Civ Eng

Jiang LH, Malhotra VM (2000) Reduction in water demand of non-air-entrained concrete incorporating large volumes of fly ash. Cem Concr Res. https://doi.org/10.1016/S0008-8846(00)00397-5

Joshaghani A, Moeini MA (2018) Evaluating the Effects of Sugarcane-Bagasse Ash and Rice-Husk Ash on the Mechanical and Durability Properties of Mortar. J Mater Civ Eng.

https://doi.org/10.1061/(asce)mt.1943-5533.0002317

Kabay N, Tufekci MM, Kizilkanat AB, Oktay D (2015) Properties of concrete with pumice powder and fly ash as cement replacement materials. Constr Build Mater. https://doi.org/10.1016/j.conbuildmat.2015.03.026 
Kameshwar P, Athira G, Bahurudeen A, Nanthagopalan P (2020) Suitable pretreatment process for rice husk ash towards dosage optimization and its effect on properties of cementitious mortar. Struct Concr. https://doi.org/10.1002/suco.202000227

Kanthe VN, Deo SV, Murmu M (2018) Effect of fly ash and rice husk ash on strength and durability of binary and ternary blend cement mortar. Asian J Civ Eng. https://doi.org/10.1007/s42107-018-0076-6

Kaplan G, Gulcan A, Cagdas B, Bayraktar OY (2021) The impact of recycled coarse aggregates obtained from waste concretes on lightweight pervious concrete properties. Environ Sci Pollut Res. https://doi.org/10.1007/s11356-020-11881-y

Karataş M, Benli A, Ergin A (2017) Influence of ground pumice powder on the mechanical properties and durability of self-compacting mortars. Constr Build Mater. https://doi.org/10.1016/j.conbuildmat.2017.05.220

Khan R, Jabbar A, Ahmad I et al (2012) Reduction in environmental problems using rice-husk ash in concrete. Constr Build Mater. https://doi.org/10.1016/j.conbuildmat.2011.11.028

Kiliç A, Sertabipoهlu Z (2015) Effect of heat treatment on pozzolanic activity of volcanic pumice used as cementitious material. Cem Concr Compos. https://doi.org/10.1016/j.cemconcomp.2014.12.006

Kizilkanat AB, Oktay D, Kabay N, Tufekci MM (2016) Comparative Experimental Study of Mortars Incorporating Pumice Powder or Fly Ash. J Mater Civ Eng. https://doi.org/10.1061/(asce)mt.19435533.0001407

Koksal F, Sahin Y, Gencel O (2020) Influence of expanded vermiculite powder and silica fume on properties of foam concretes. Constr Build Mater. https://doi.org/10.1016/j.conbuildmat.2020.119547

Le HT, Ludwig HM (2016) Effect of rice husk ash and other mineral admixtures on properties of selfcompacting high performance concrete. Mater Des. https://doi.org/10.1016/j.matdes.2015.09.120

Lesovik V, Voronov V, Glagolev E et al (2020) Improving the behaviors of foam concrete through the use of composite binder. J Build Eng. https://doi.org/10.1016/j.jobe.2020.101414

Madandoust R, Ranjbar MM, Moghadam HA, Mousavi SY (2011) Mechanical properties and durability assessment of rice husk ash concrete. Biosyst Eng.

https://doi.org/10.1016/j.biosystemseng.2011.07.009

Masi G, Rickard WDA, Vickers L et al (2014) A comparison between different foaming methods for the synthesis of light weight geopolymers. Ceram Int. https://doi.org/10.1016/j.ceramint.2014.05.108

Meddah MS, Praveenkumar TR, Vijayalakshmi MM et al (2020) Mechanical and microstructural characterization of rice husk ash and Al2O3 nanoparticles modified cement concrete. Constr Build Mater. https://doi.org/10.1016/j.conbuildmat.2020.119358 
Mehta PK (2004) High-performance, high-volume fly ash concrete for sustainable development. Içinde: International Workshop on Sustainable Development and Concrete Technology

Mehta PK (1989) Pozzolanic and Cementitious By-Products in Concrete - Another Look. ACl Spec Publ 114

Mehta PK (1999) Concrete technology for sustainable development

Mohseni E, Yazdi MA, Miyandehi BM et al (2017) Combined Effects of Metakaolin, Rice Husk Ash, and Polypropylene Fiber on the Engineering Properties and Microstructure of Mortar. J Mater Civ Eng. https://doi.org/10.1061/(asce)mt.1943-5533.0001867

Nambiar EKK, Ramamurthy K (2009) Shrinkage Behavior of Foam Concrete. J Mater Civ Eng. https://doi.org/10.1061/(asce)0899-1561(2009)21:11(631)

Nambiar EKK, Ramamurthy K (2006) Influence of filler type on the properties of foam concrete. Cem Concr Compos. https://doi.org/10.1016/j.cemconcomp.2005.12.001

Nambiar EKK, Ramamurthy K (2007) Sorption characteristics of foam concrete. Cem Concr Res. https://doi.org/10.1016/j.cemconres.2007.05.010

Namsone E, Korjakins A, Sahmenko G, Sinka M (2017) The environmental impacts of foamed concrete production and exploitation. Içinde: IOP Conference Series: Materials Science and Engineering

Narasimman R, Vijayan S, Prabhakaran K (2014) Carbon particle induced foaming of molten sucrose for the preparation of carbon foams. Mater Sci Eng B Solid-State Mater Adv Technol.

https://doi.org/10.1016/j.mseb.2014.08.007

Nehdi ML, Bassuoni MT (2008) Durability of self-consolidating concrete to combined effects of sulphate attack and frost action. Mater Struct Constr. https://doi.org/10.1617/s11527-008-9356-z

Netinger I, Vra?evi? M, Ranogajec J, Vu? eti? S (2014) Evaluation of brick resistance to freeze / thaw cycles according to indirect procedures | Progeria otpomosti opeke na cikluse smrzavanja/ odmrzavanja prema indirektnim postupcima. Gradjevinar. https://doi.org/10.14256/JCE.956.2013

Olutoge FA, Adesina PA (2019) Effects of rice husk ash prepared from charcoal-powered incinerator on the strength and durability properties of concrete. Constr Build Mater.

https://doi.org/10.1016/j.conbuildmat.2018.11.138

Özbay E, Karahan O, Lachemi M et al (2012) Investigation of properties of engineered cementitious composites incorporating high volumes of fly ash and metakaolin. ACI Mater J. https://doi.org/10.14359/51684088 
Panesar DK (2013) Cellular concrete properties and the effect of synthetic and protein foaming agents. Constr Build Mater. https://doi.org/10.1016/j.conbuildmat.2013.03.024

Park KB, Kwon SJ, Wang XY (2016) Analysis of the effects of rice husk ash on the hydration of cementitious materials. Constr Build Mater. https://doi.org/10.1016/j.conbuildmat.2015.12.086

Pasupathy K, Ramakrishnan S, Sanjayan J (2020) Enhancing the mechanical and thermal properties of aerated geopolymer concrete using porous lightweight aggregates. Constr Build Mater. https://doi.org/10.1016/j.conbuildmat.2020.120713

Patel YJ, Shah N (2018) Enhancement of the properties of Ground Granulated Blast Furnace Slag based Self Compacting Geopolymer Concrete by incorporating Rice Husk Ash. Constr Build Mater. https://doi.org/10.1016/j.conbuildmat.2018.03.166

Pode R (2016) Potential applications of rice husk ash waste from rice husk biomass power plant. Renew. Sustain. Energy Rev

Rafieizonooz M, Mirza J, Salim MR et al (2016) Investigation of coal bottom ash and fly ash in concrete as replacement for sand and cement. Constr Build Mater.

https://doi.org/10.1016/j.conbuildmat.2016.04.080

Raj A, Sathyan D, Mini KM (2019) Physical and functional characteristics of foam concrete: A review. Constr. Build. Mater

Sadrmomtazi A, Sobhani J, Mirgozar MA, Najimi M (2012) Properties of multi-strength grade EPS concrete containing silica fume and rice husk ash. Constr Build Mater.

https://doi.org/10.1016/j.conbuildmat.2012.02.049

Seraj S, Cano R, Ferron RD, Juenger MCG (2017) The role of particle size on the performance of pumice as a supplementary cementitious material. Cem Concr Compos.

https://doi.org/10.1016/j.cemconcomp.2017.03.009

Shaikuthali SA, Mannan MA, Dawood ET et al (2019) Workability and compressive strength properties of normal weight concrete using high dosage of fly ash as cement replacement. J Build Pathol Rehabil. https://doi.org/10.1007/s41024-019-0065-5

Shanmuga Priya T, Mehra A, Jain S, Kakria K (2021) Effect of graphene oxide on high-strength concrete induced with rice husk ash: mechanical and durability performance. Innov Infrastruct Solut. https://doi.org/10.1007/s41062-020-00378-9

She W, Du Y, Zhao G et al (2018) Influence of coarse fly ash on the performance of foam concrete and its application in high-speed railway roadbeds. Constr Build Mater.

https://doi.org/10.1016/j.conbuildmat.2018.02.207 
Shi C, Stegemann JA (2000) Acid corrosion resistance of different cementing materials. Cem Concr Res. https://doi.org/10.1016/S0008-8846(00)00234-9

Siddique R (2012) Properties of concrete made with volcanic ash. Resour. Conserv. Recycl

Singh R, Srivastava M, Shukla A (2016) Environmental sustainability of bioethanol production from rice straw in India: A review. Renew. Sustain. Energy Rev

Sun C, Zhu Y, Guo J et al (2018) Effects of foaming agent type on the workability, drying shrinkage, frost resistance and pore distribution of foamed concrete. Constr Build Mater.

https://doi.org/10.1016/j.conbuildmat.2018.08.019

Thomas BS (2018) Green concrete partially comprised of rice husk ash as a supplementary cementitious material - A comprehensive review. Renew. Sustain. Energy Rev

Tikalsky PJ, Huffman MV, Barger GM (2001) Use of Raw or Processed Natural Pozzolans in Concrete Tikalsky PJ, Pospisil J, MacDonald W (2004) A method for assessment of the freeze-thaw resistance of preformed foam cellular concrete. Cem Concr Res. https://doi.org/10.1016/j.cemconres.2003.11.005

Toklu K (2021) Investigation of Mechanical and Durability Behaviour of High Strength Cementitious Composites Containing Natural Zeolite and Blast-furnace Slag. Silicon. https://doi.org/10.1007/s12633020-00866-8

Xu W, Lo YT, Ouyang D et al (2015) Effect of rice husk ash fineness on porosity and hydration reaction of blended cement paste. Constr Build Mater. https://doi.org/10.1016/j.conbuildmat.2015.04.030

Yang W, Xue Y, Wu S et al (2016) Performance investigation and environmental application of basic oxygen furnace slag - Rice husk ash based composite cementitious materials. Constr Build Mater. https://doi.org/10.1016/j.conbuildmat.2016.07.051

Younes MM, Abdel-Rahman HA, Khattab MM (2018) Utilization of rice husk ash and waste glass in the production of ternary blended cement mortar composites. J Build Eng.

https://doi.org/10.1016/j.jobe.2018.07.001

Zeyad AM, Almalki A (2021) Role of particle size of natural pozzolanic materials of volcanic pumice: flow properties, strength, and permeability. Arab J Geosci. https://doi.org/10.1007/s12517-020-06443-y

Zeyad AM, Tayeh BA, Yusuf MO (2019) Strength and transport characteristics of volcanic pumice powder based high strength concrete. Constr Build Mater. https://doi.org/10.1016/j.conbuildmat.2019.05.026

\section{Figures}



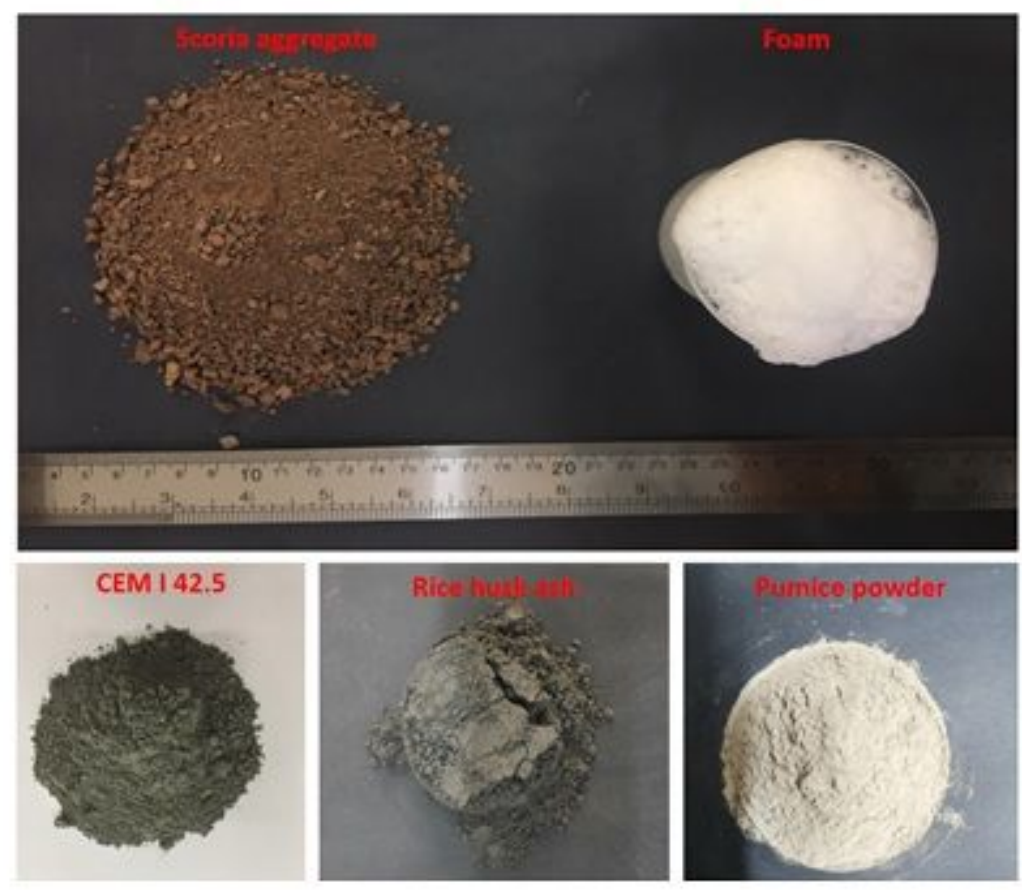

\section{Figure 1}

Materials used in the study

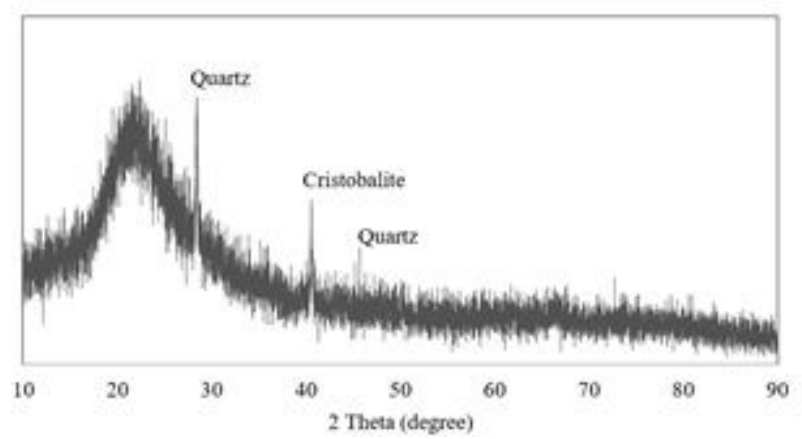

Figure 2

XRD graph for RHA 

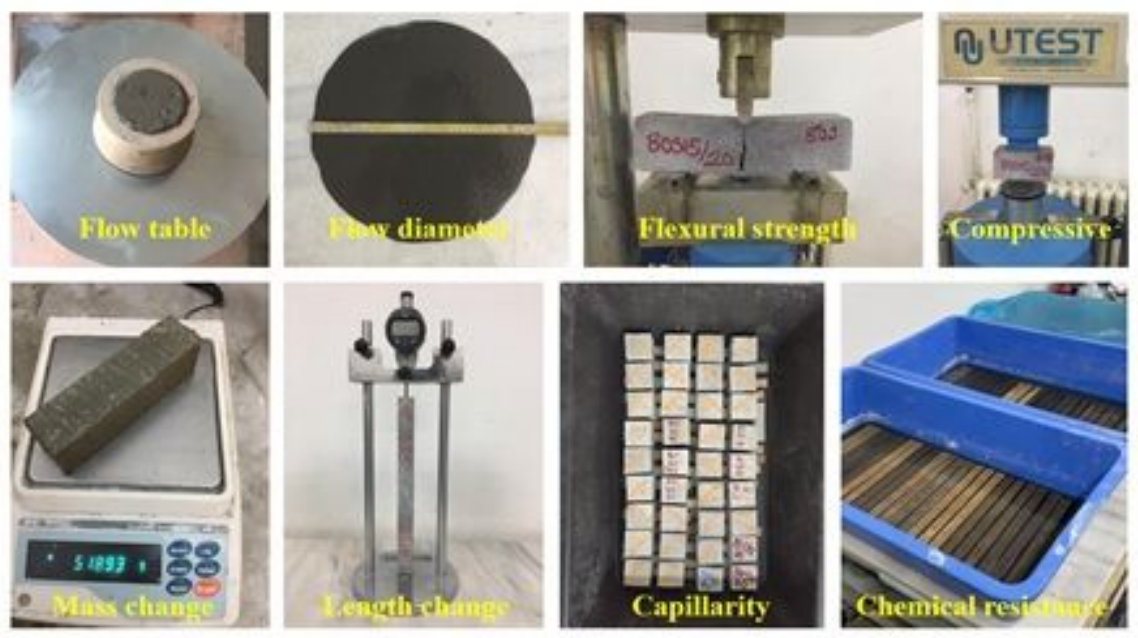

Figure 3

Testing equipment

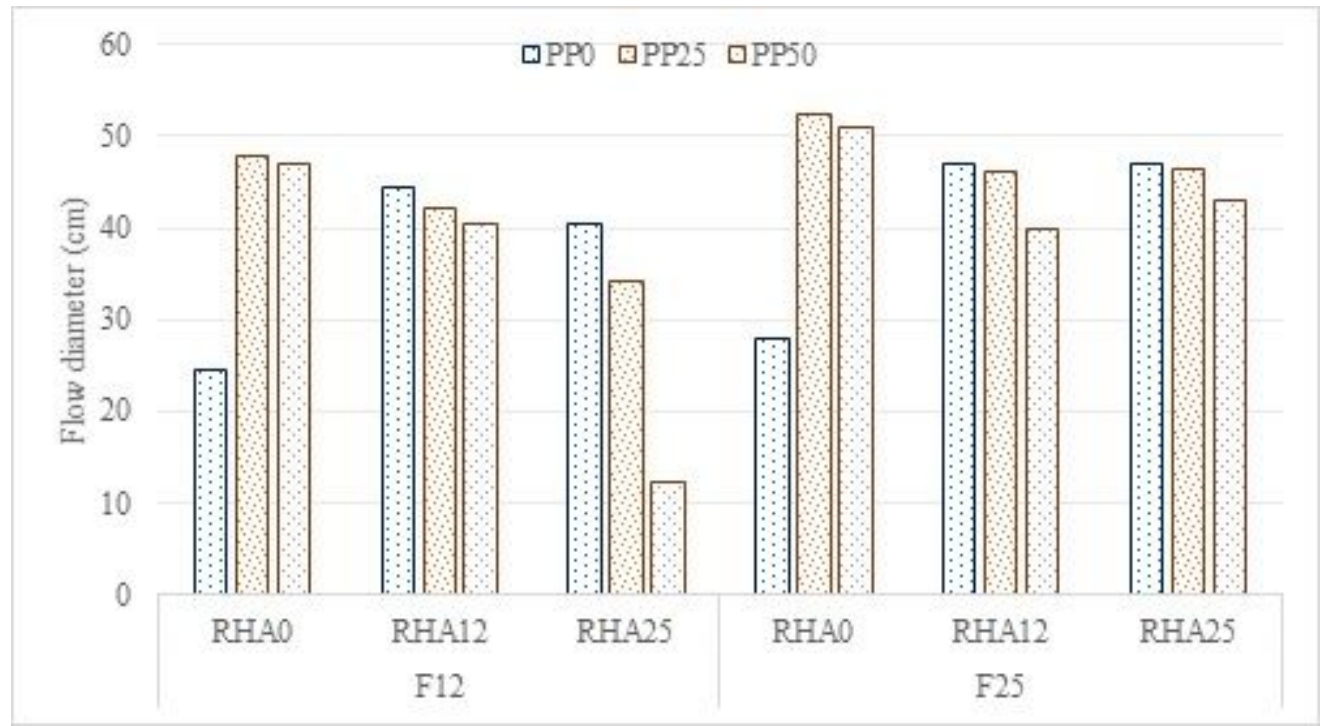

Figure 4

Flow diameters of cement-based composites 


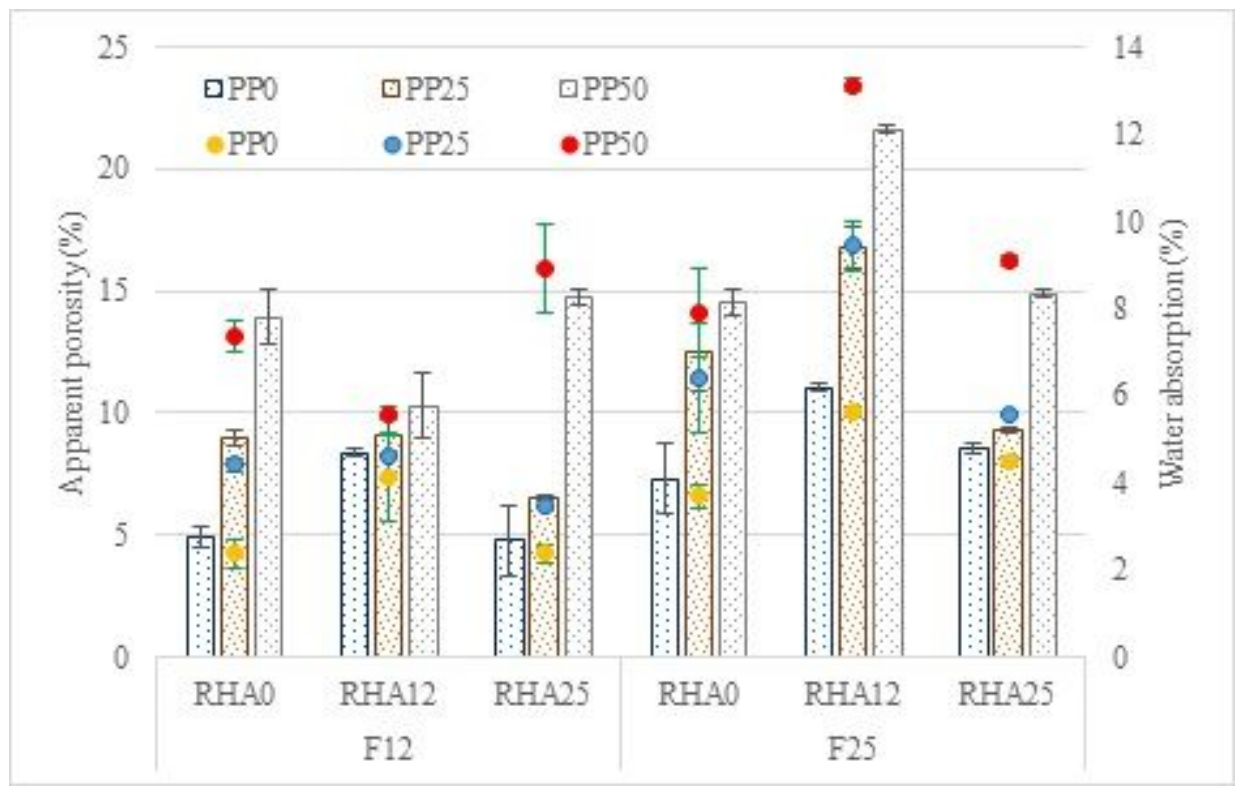

Figure 5

Physical properties

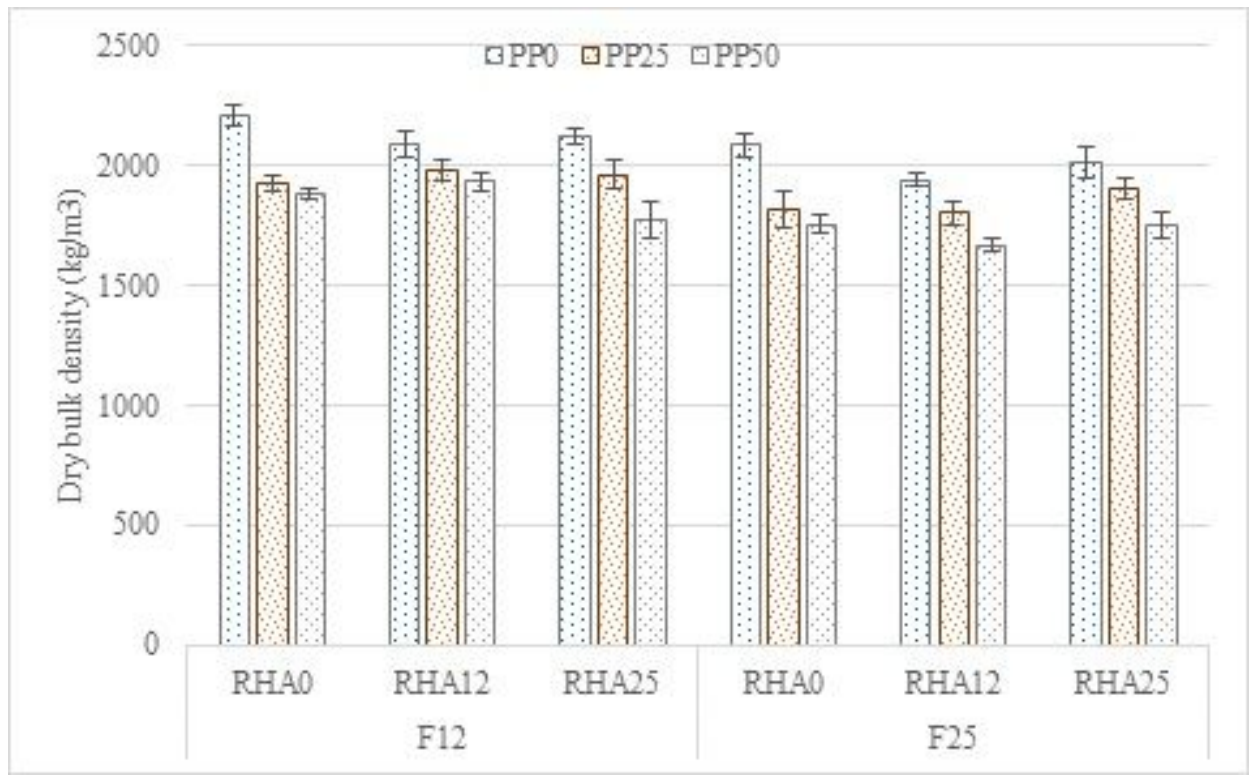

Figure 6

Dry bulk density of cement-based composites 


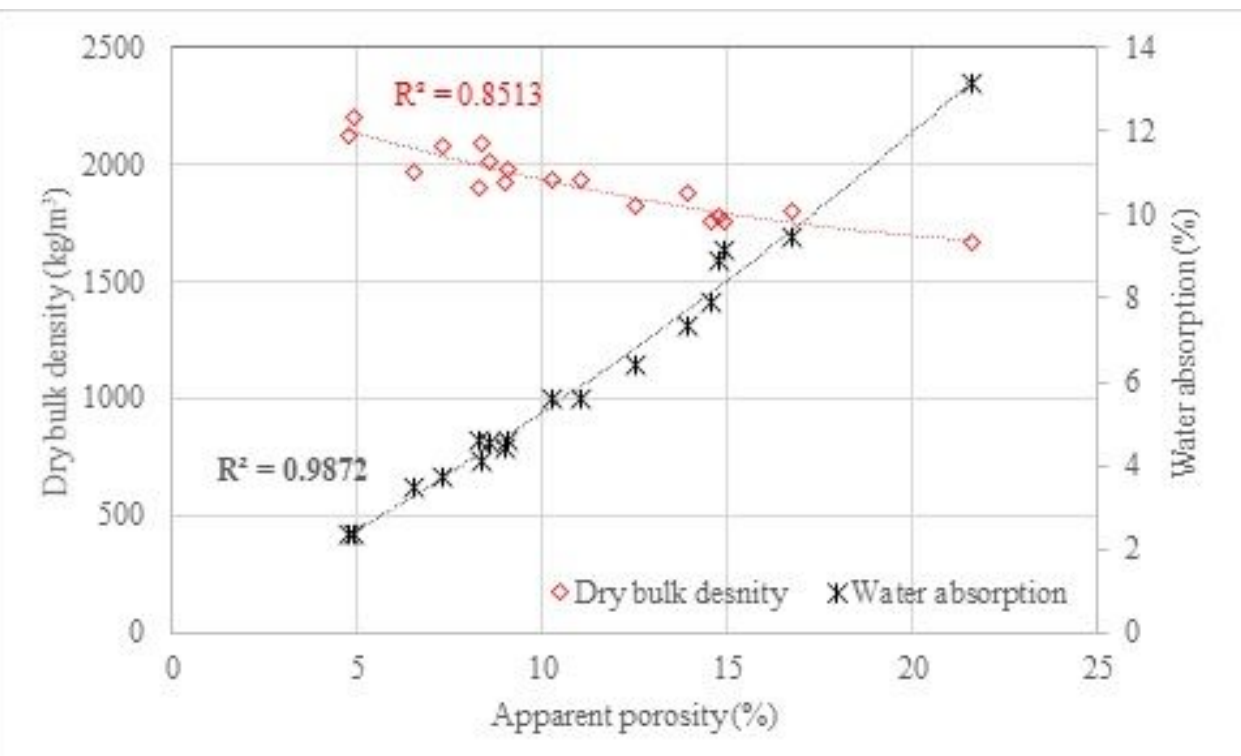

Figure 7

Correlation of physical properties

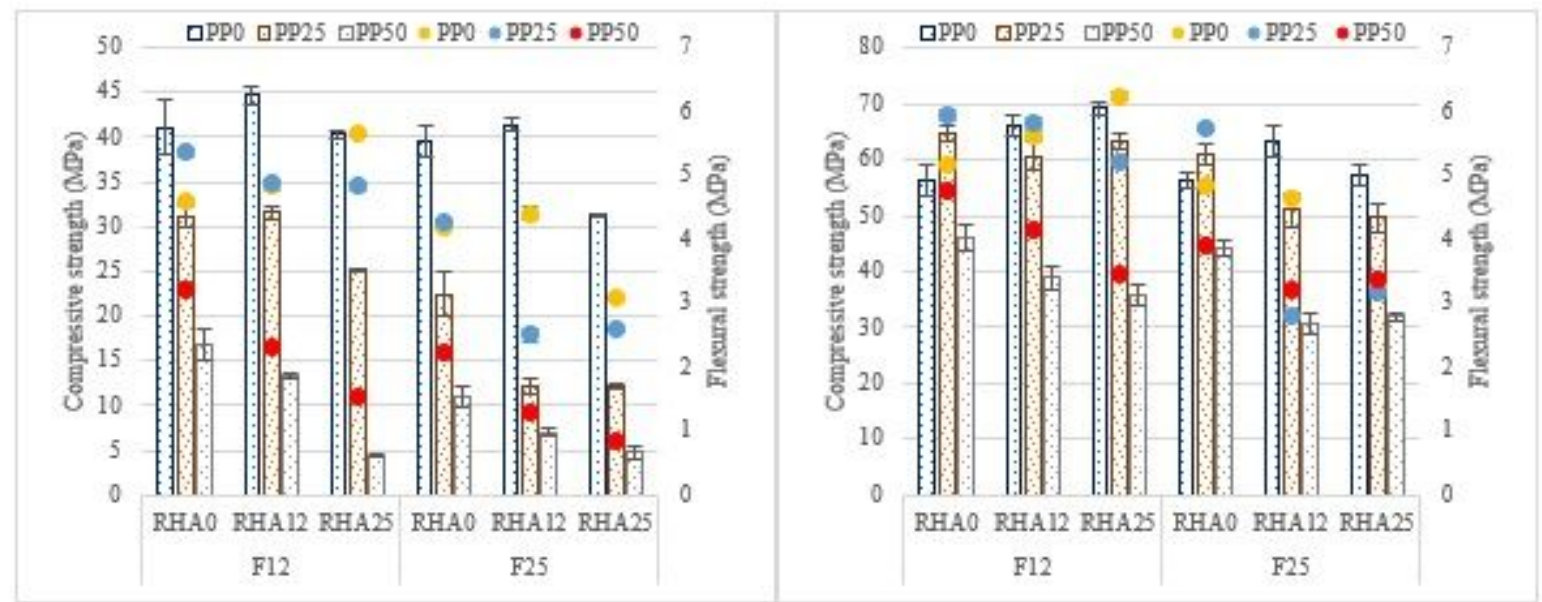

(a) 1 Day

(b) 7 Day

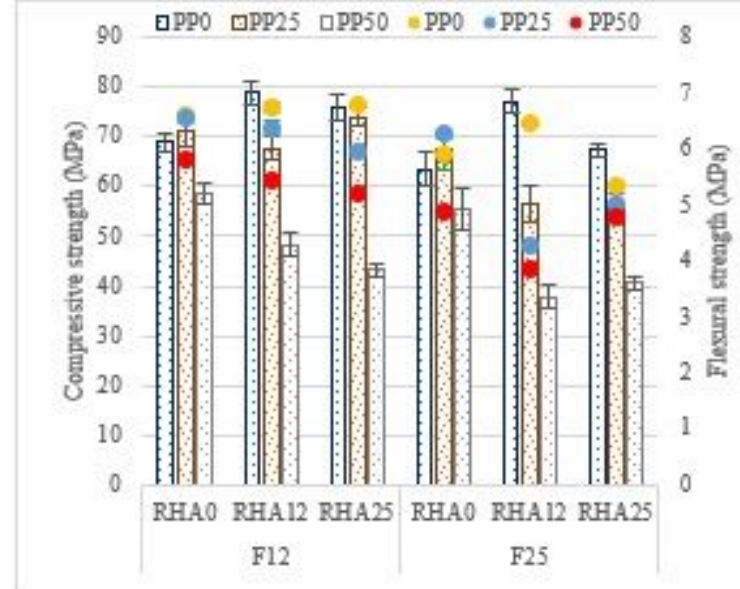

(c) 28 Day

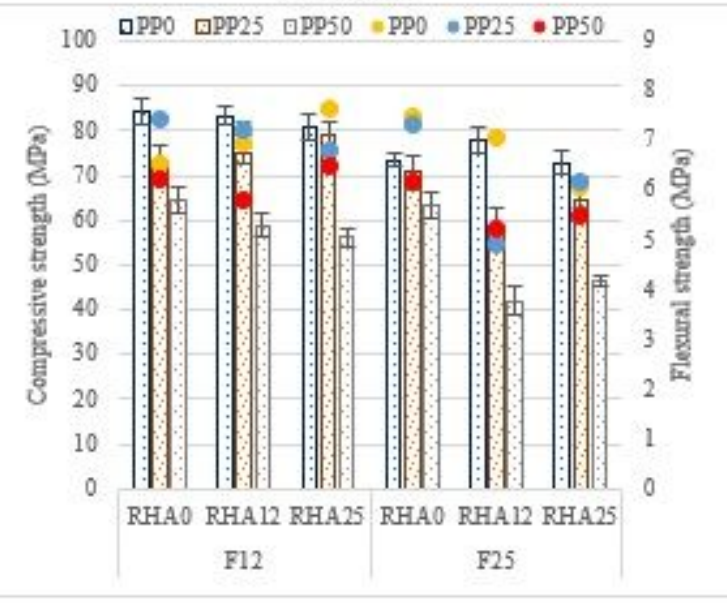

(d) 91 Day

Figure 8 
Compressive and flexural strength of cement-based composites

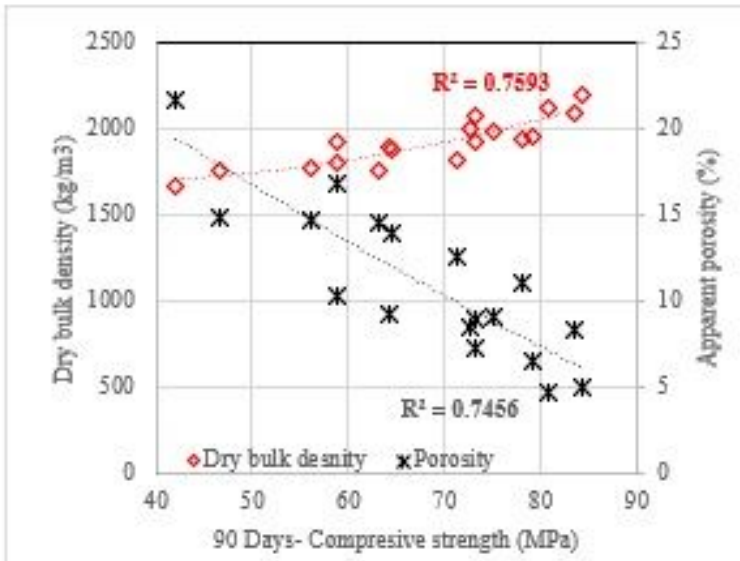

(a) Compressive strength-Physical properties

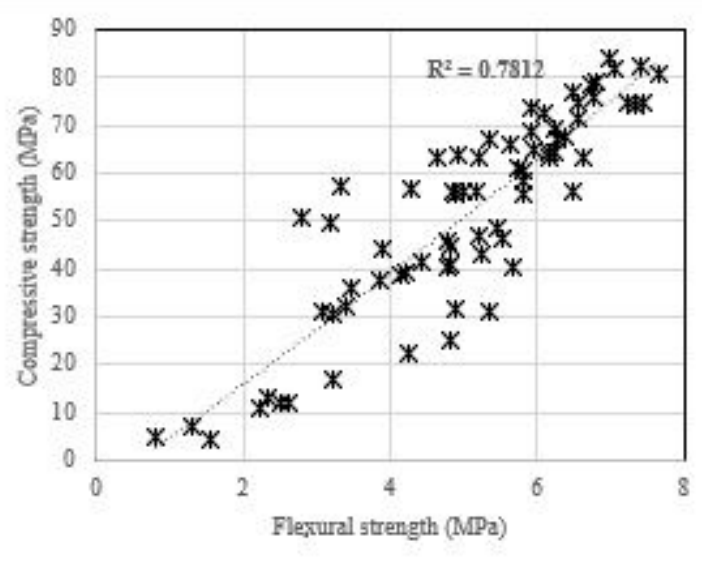

(b) Compressive strength-Flexural strength

\section{Figure 9}

Correlations of compressive strength

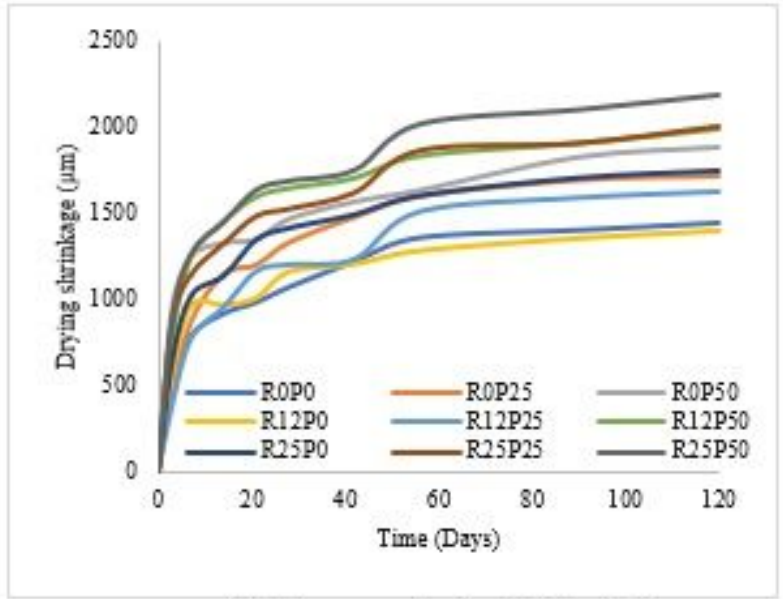

(a) Foam content: $12.5 \mathrm{~kg} / \mathrm{m}^{3}$

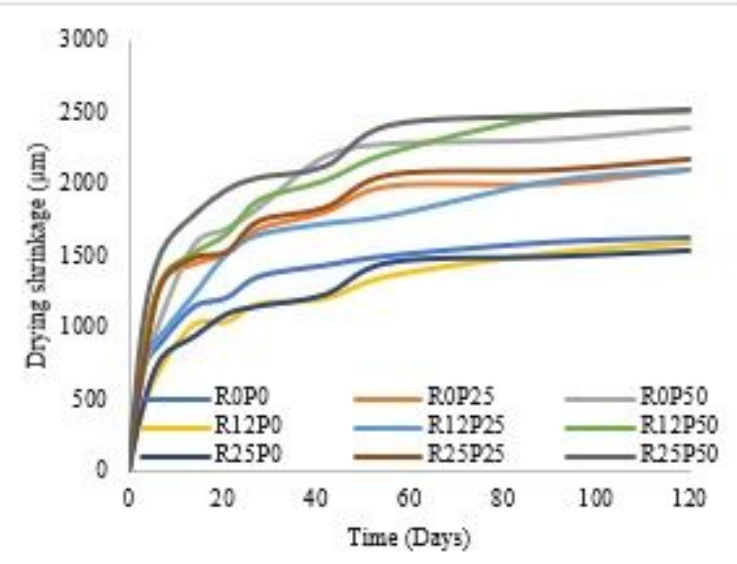

(b) Foam content: $25 \mathrm{~kg} / \mathrm{m}^{3}$

\section{Figure 10}

Drying shrinkage of mixtures 


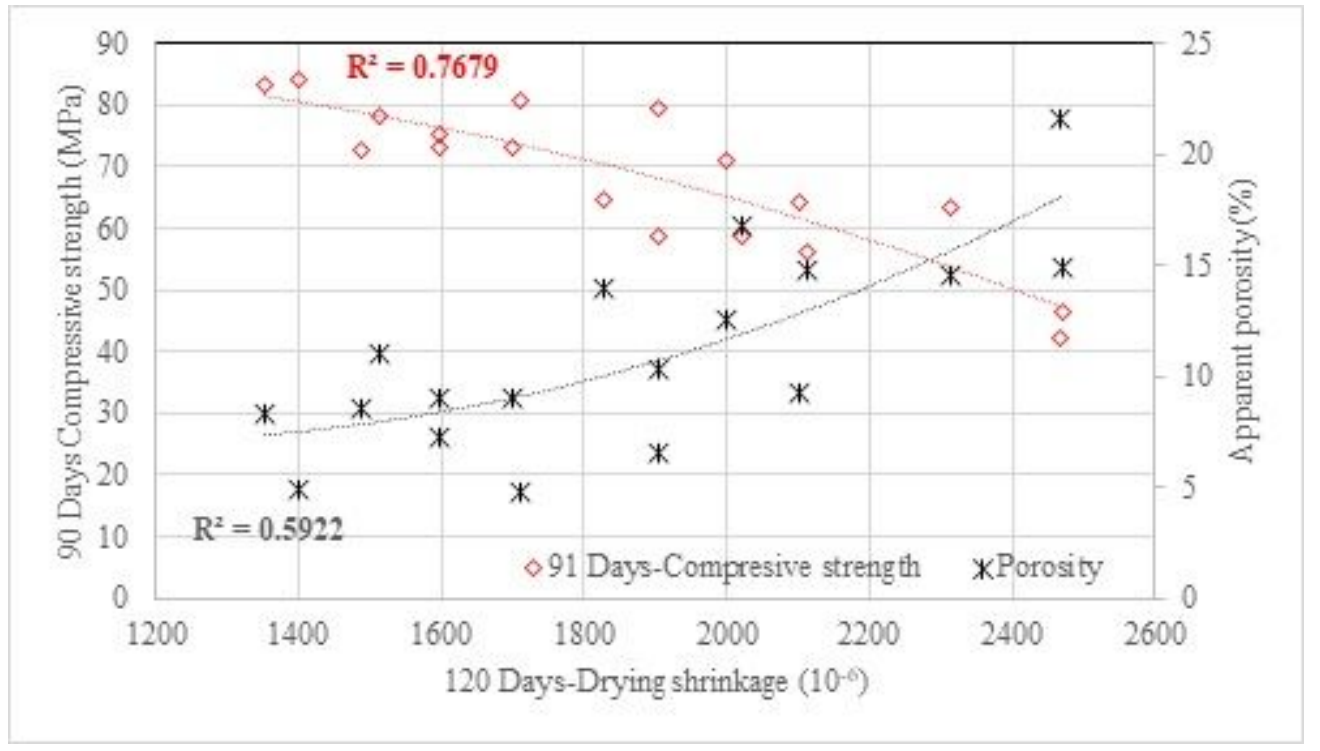

\section{Figure 11}

The relationship of drying shrinkage with compressive strength and porosity

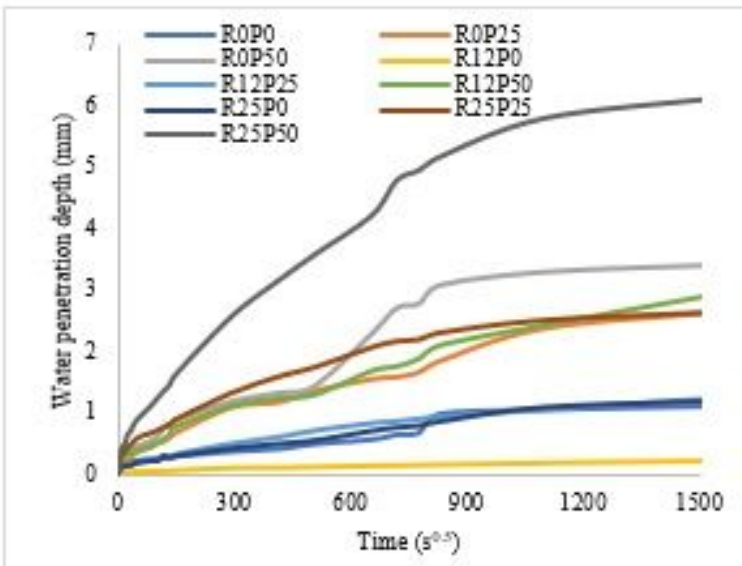

(a) Foam content: $12.5 \mathrm{~kg} / \mathrm{m}^{3}$

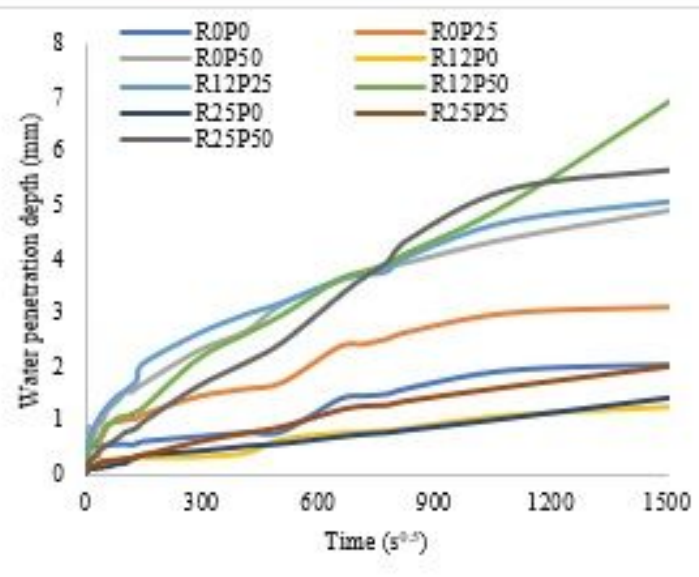

(b) Foam content: $25 \mathrm{~kg} / \mathrm{m}^{3}$

Figure 12

Water penetration depth of cement based-composites 


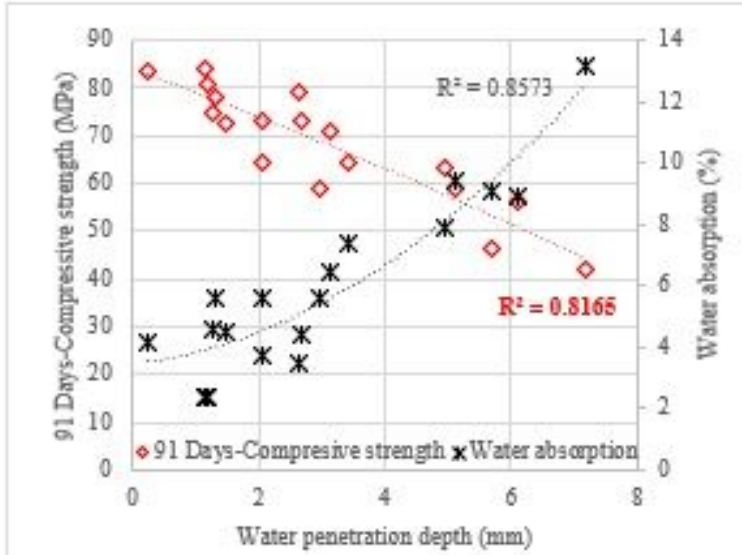

(a) Water penetration-Compressive strength

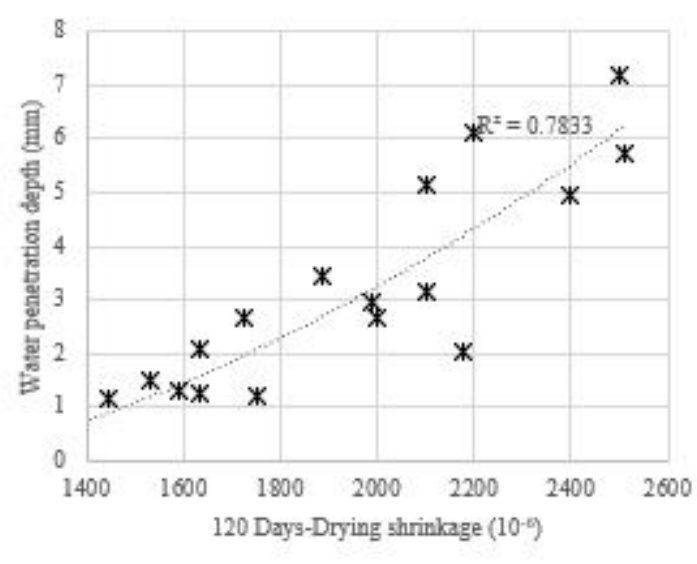

(b) Water penetration-Drying shrinkage

Figure 13

Correlations of water penetration depth

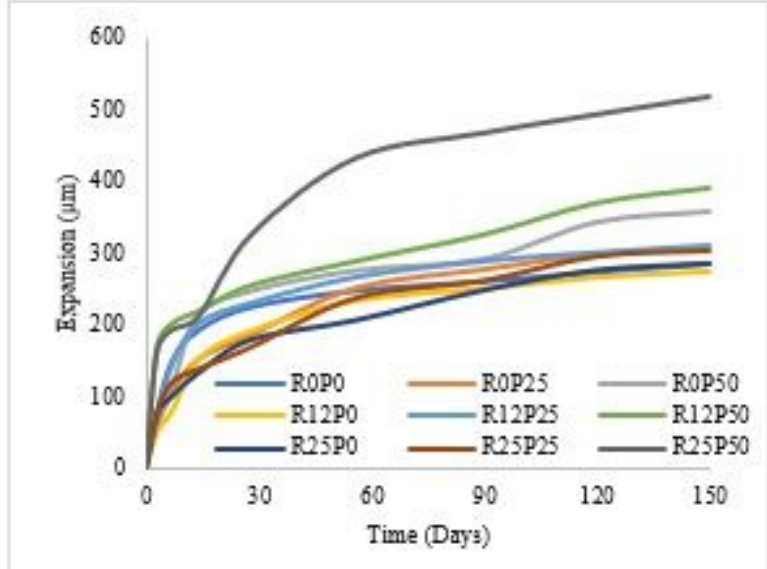

(a) Foam content: $12.5 \mathrm{~kg} / \mathrm{m}^{3}$

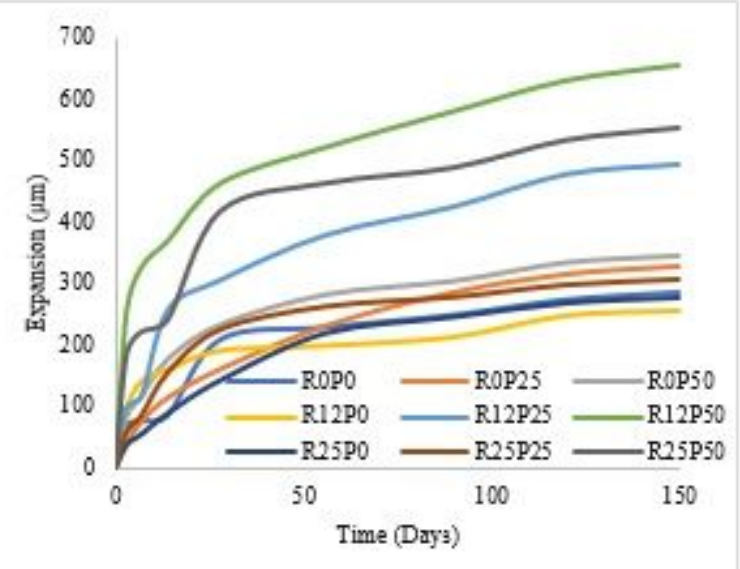

(b) Foam content: $25 \mathrm{~kg} / \mathrm{m}^{3}$

\section{Figure 14}

Sulfate resistance of cement based-composites

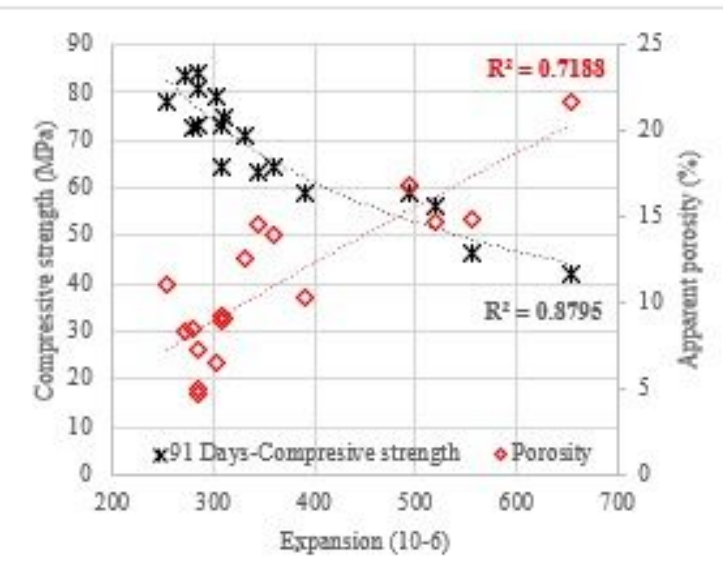

(a) Expansion-Porosity

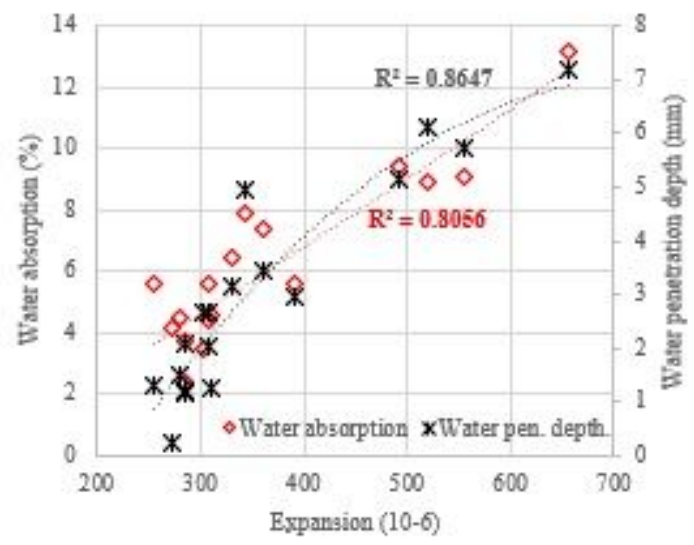

(b) Expansion-Water absorption 
Figure 15

Correlations of the expansion caused by sulfate

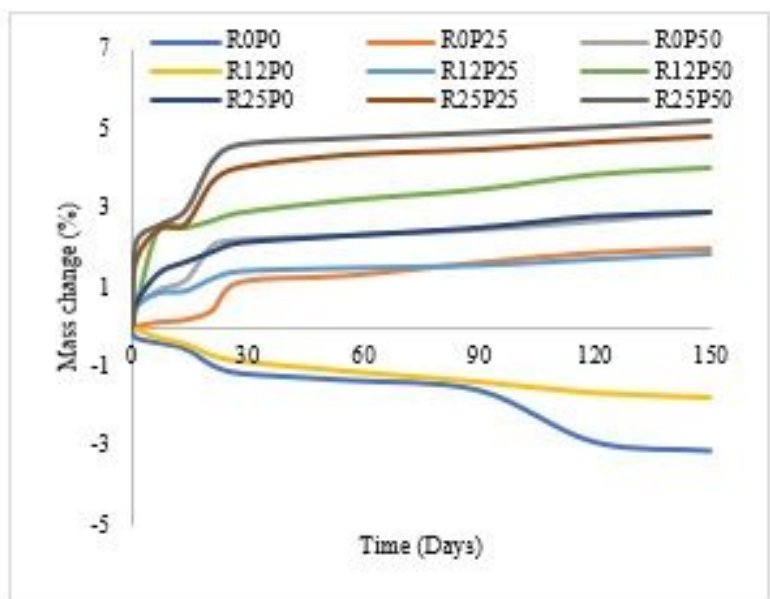

(a) Foam content: $12.5 \mathrm{~kg} / \mathrm{m}^{3}$

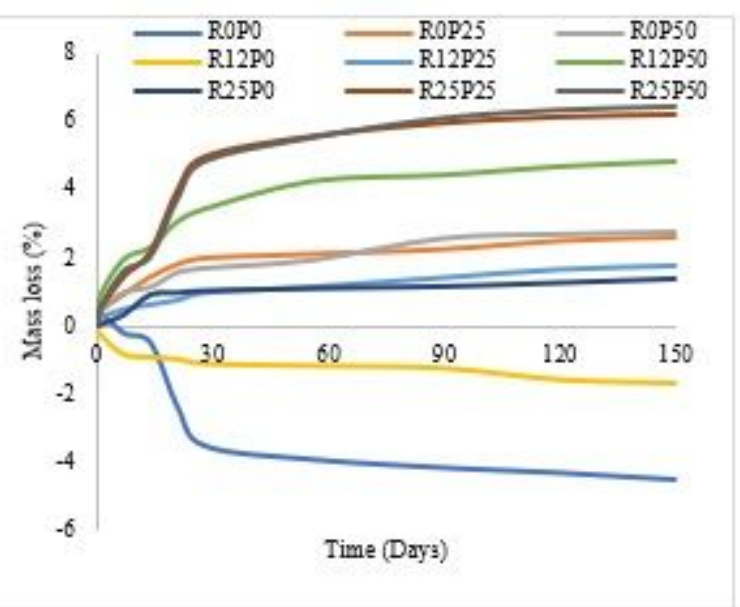

(b) Foam content: $25 \mathrm{~kg} / \mathrm{m}^{3}$

\section{Figure 16}

Mass changes of cement based composites exposed to $\mathrm{H} 2 \mathrm{SO} 4$

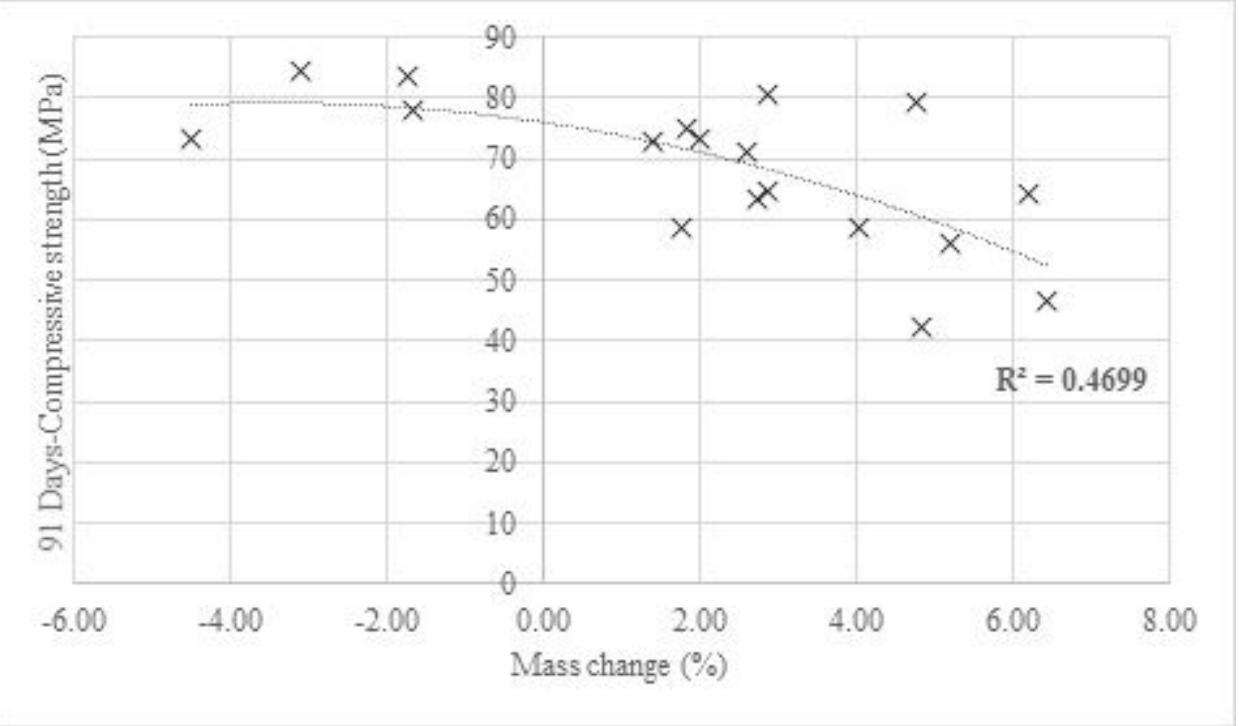

\section{Figure 17}

Relationship between compressive strength and mass change 


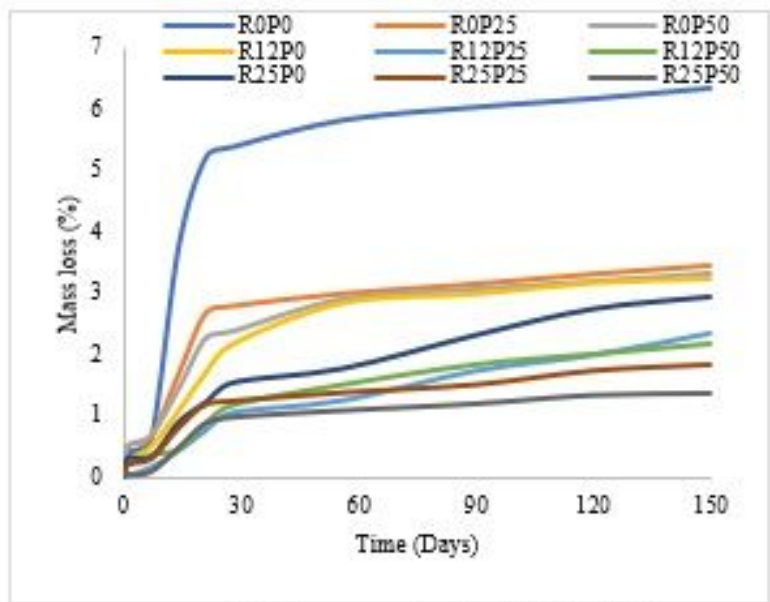

(a) Foam content: $12.5 \mathrm{~kg} / \mathrm{m}^{3}$

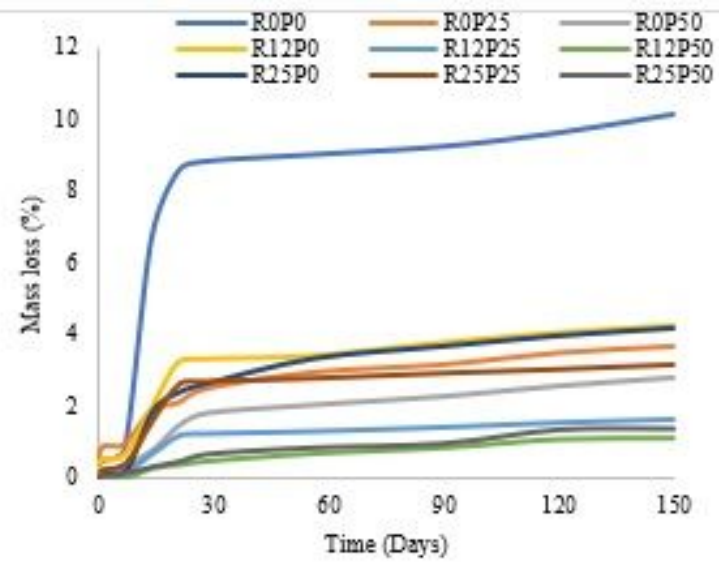

(b) Foam content: $25 \mathrm{~kg} / \mathrm{m}^{3}$

\section{Figure 18}

Mass changes of cement based composites exposed to $\mathrm{HCl}$

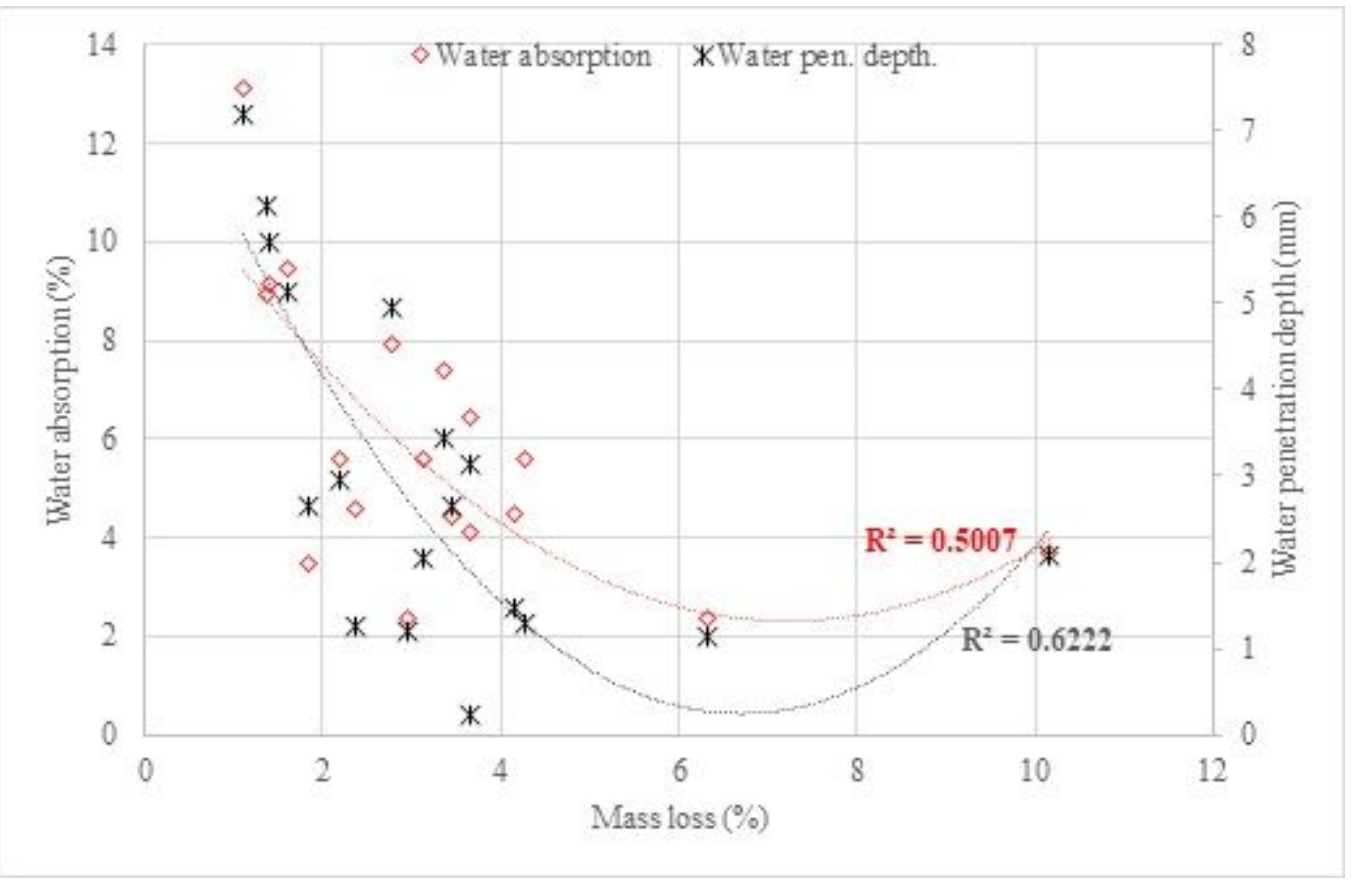

Figure 19

Correlations of mass loss 


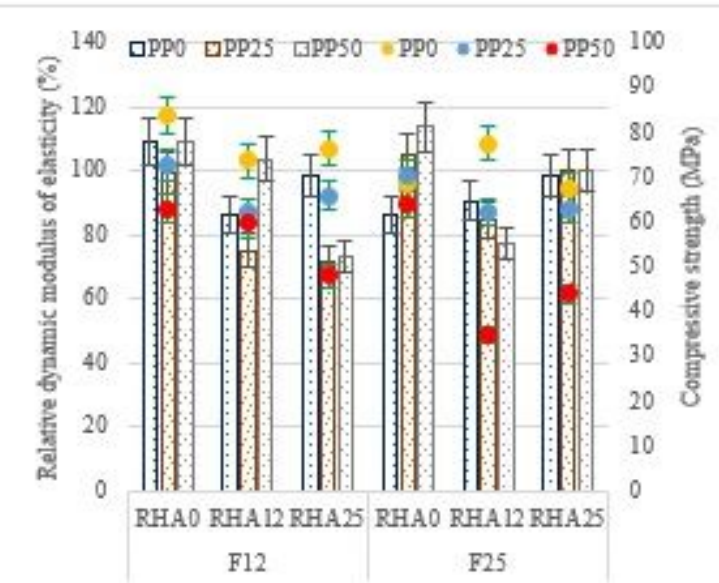

(a) After 100 cycles

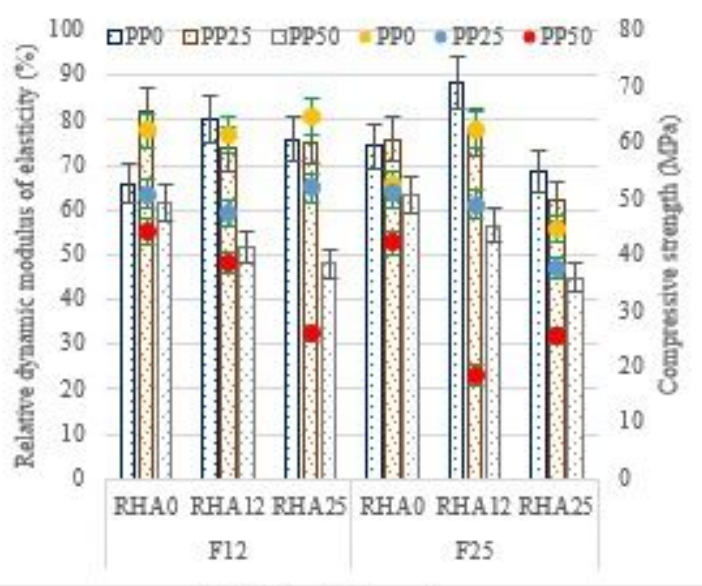

(b) After 200 cycles

\section{Figure 20}

Relative dynamic elasticity modulus and compressive strength of cement-based composites

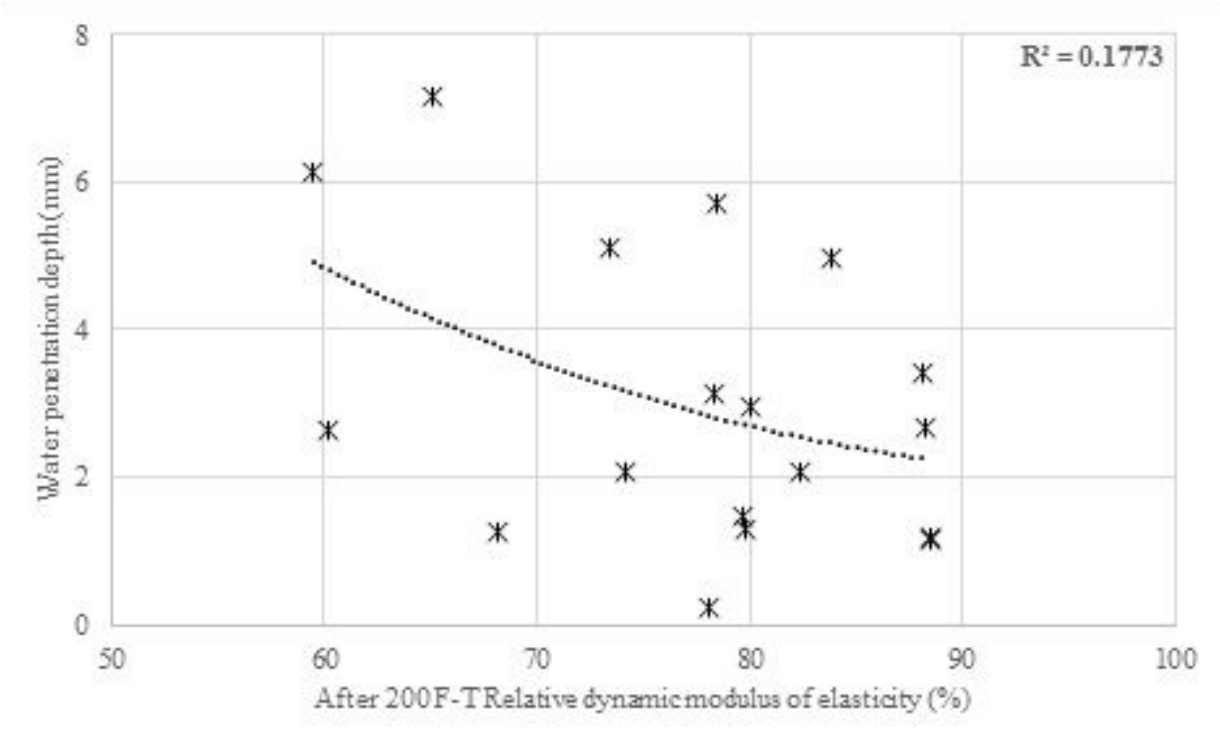

Figure 21

Water penetration depth-relative dynamic modulus of elasticity relationship 


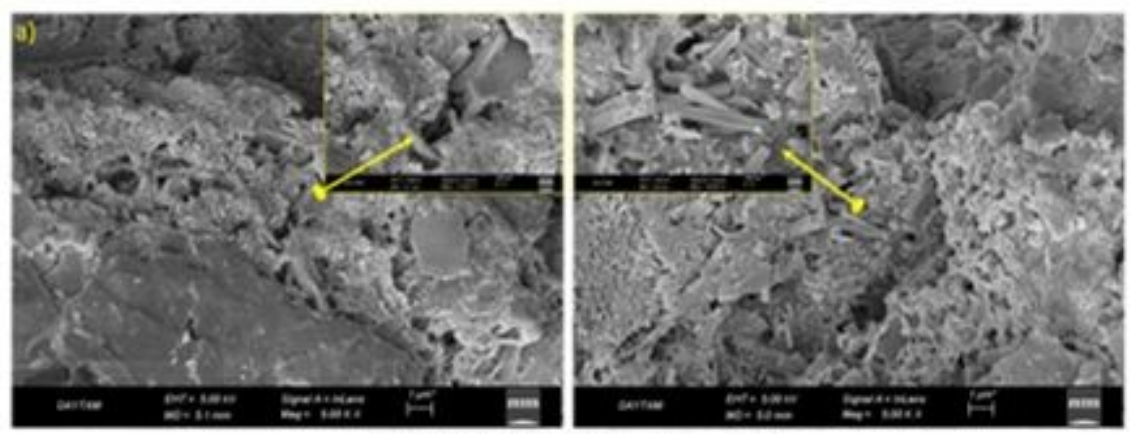

a) $0 \%$ RHA-0\%PP-F12.5 kg/m 3

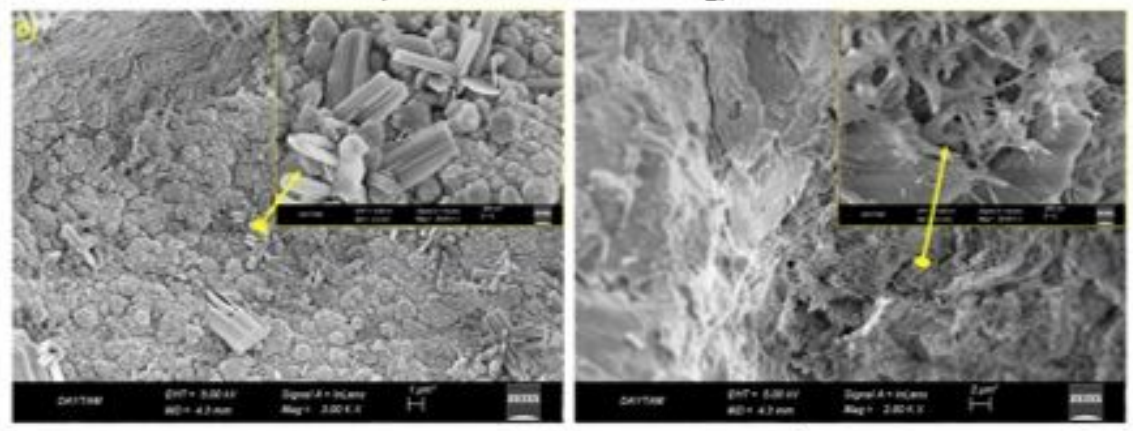

b) $12.5 \%$ RHA-25\%PP-F12.5 kg/m $\mathrm{m}^{3}$

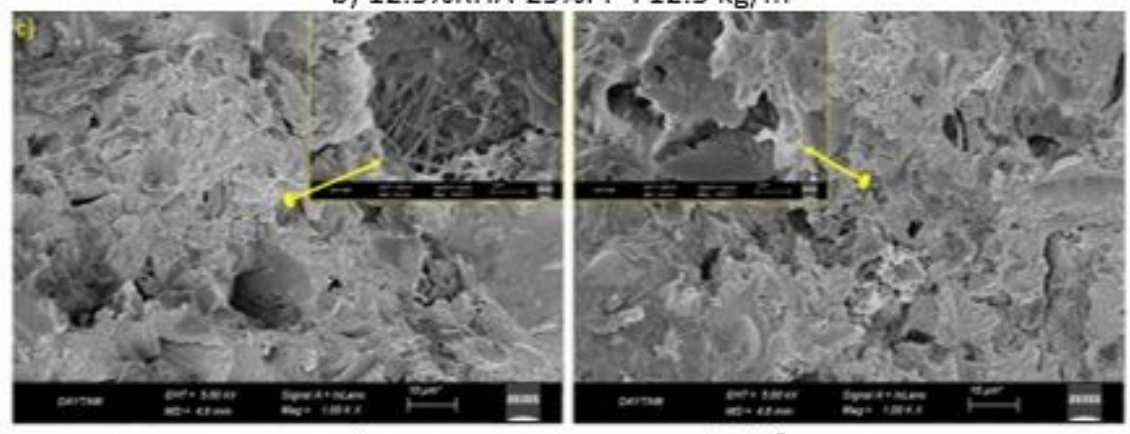

c) $25 \% \mathrm{RHA}-50 \% \mathrm{PP}-\mathrm{F} 25.0 \mathrm{~kg} / \mathrm{m}^{3}$

Figure 22

Cement-based composites microstructures exposed to sodium sulfate 


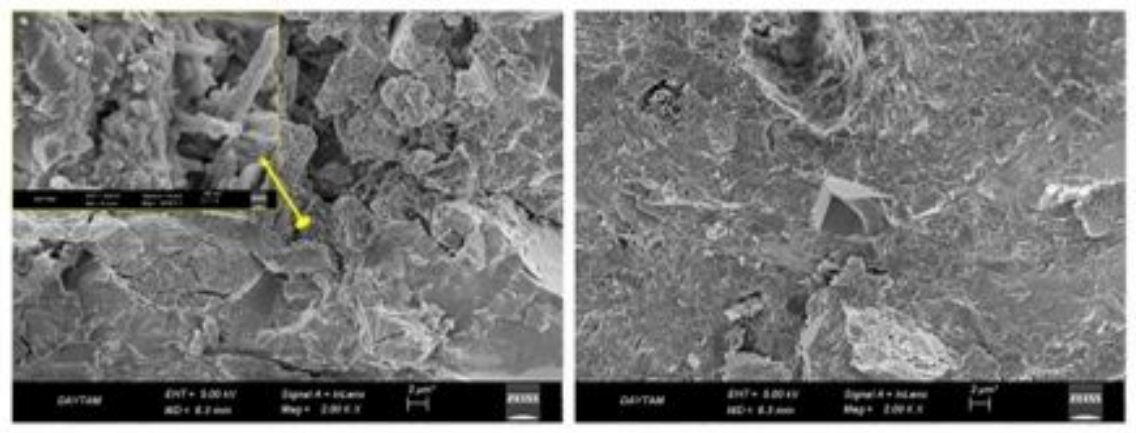

a) $0 \%$ RHA-0\%PP-F12.5 kg/m 3

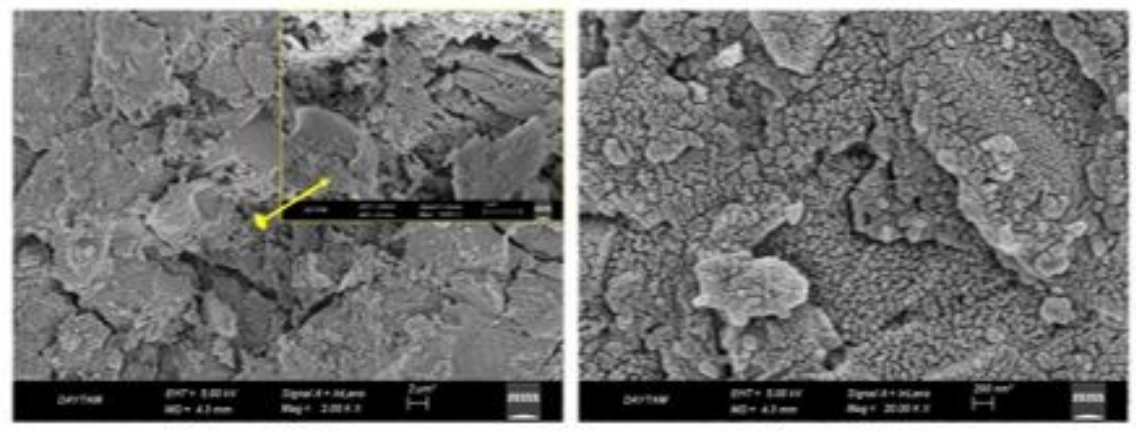

b) $12.5 \%$ RHA- $25 \% \mathrm{PP}-\mathrm{F} 12.5 \mathrm{~kg} / \mathrm{m}^{3}$

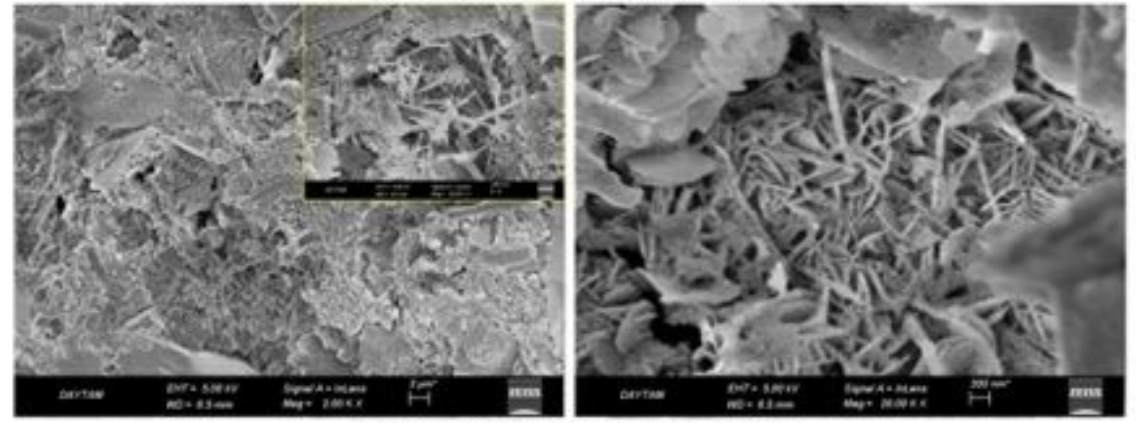

c) $25 \%$ RHA-50\%PP-F $25.0 \mathrm{~kg} / \mathrm{m}^{3}$

Figure 23

Cement-based composites microstructures exposed to hydrochloric acid 


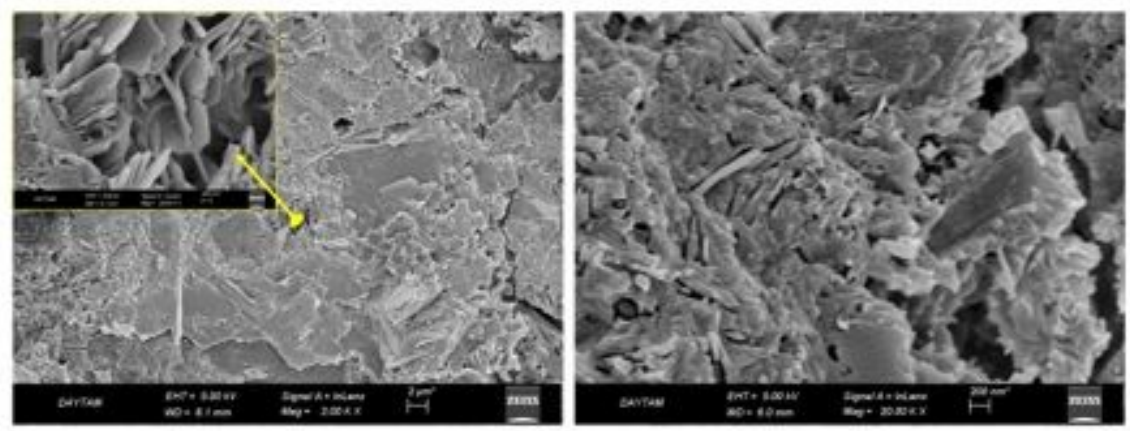

a) $0 \%$ RHA-0\%PP-F12.5 kg/m 3

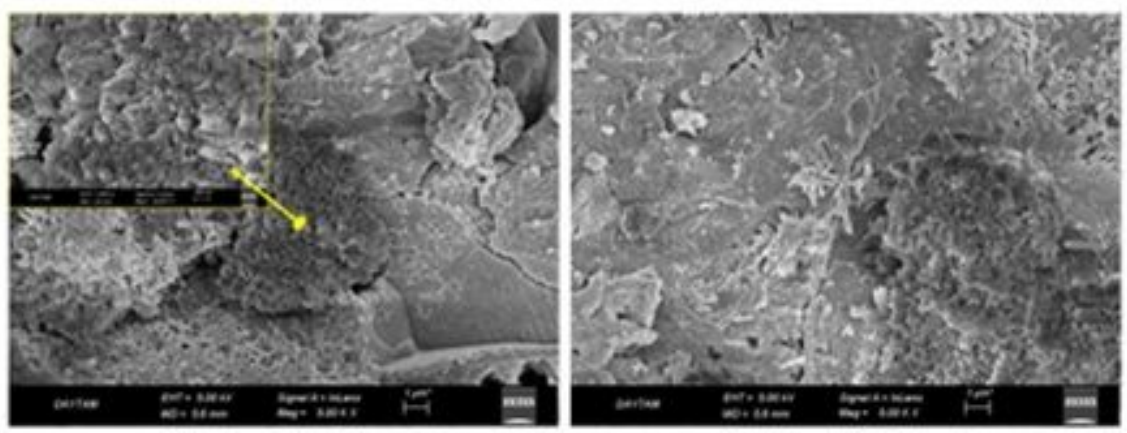

b) $12.5 \%$ RHA-25\%PP-F12.5 kg/m ${ }^{3}$

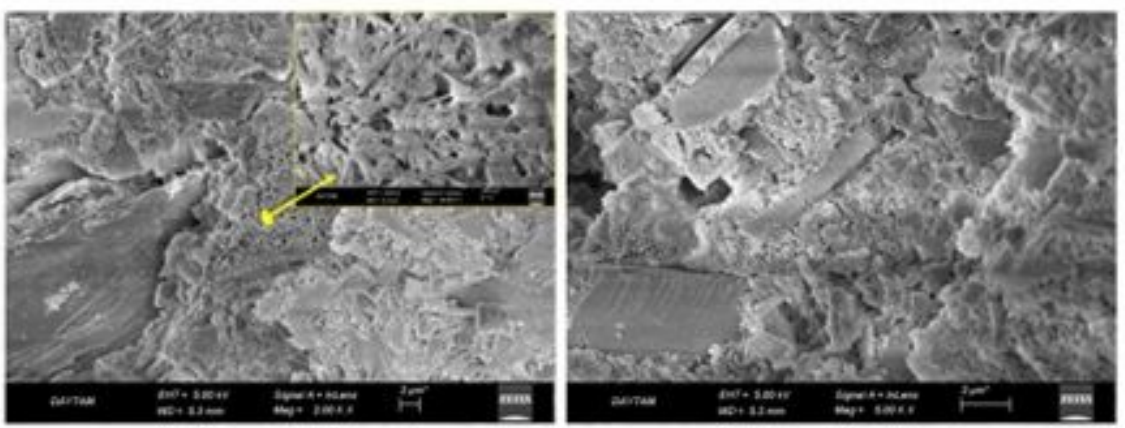

c) $25 \%$ RHA- $50 \%$ PP-F $25.0 \mathrm{~kg} / \mathrm{m}^{3}$

Figure 24

Cement-based composites microstructures exposed to sulfuric acid 